\title{
Tagging SNPs in the Excision Repair Cross-Complementing Group 4 (ERCC4) Gene Increased Risk of Cervical Squamous Cell Carcinoma (CSCC) and Modulate the Disease Outcome
}

Edyta Pawlak-Adamska ${ }^{1 *}$, Magdalena Bartosinska ${ }^{1}$, Iwona Wlodarska-Polinska ${ }^{2}$, Agnieszka Ignatowicz-Pacyna $^{3}$, Jan Kornafel ${ }^{3}$, Marcin Stepien ${ }^{3}$, Iwona Ewa Kochanowska ${ }^{4}$ and Irena Frydecka ${ }^{1}$

${ }^{1}$ Laboratory of Immunopathology, Department of Experimental Therapy, Institute of Immunology and Experimental Therapy, Polish Academy of Sciences, Wroclaw, Poland

${ }^{2}$ Euromedic Oncotherapy Walbrzych Poland, Poland

${ }^{3}$ Department of Oncology and Gynecological Oncology Clinic, Medical University, Wroclaw, Poland

${ }^{4}$ Laboratory of Immunobiology, Department of Experimental Therapy, Institute of Immunology and Experimental Therapy, Polish Academy of Sciences, Wroclaw, Poland

${ }^{*}$ Corresponding author: Pawlak-Adamska E, Laboratory of Immunopathology, Department of Experimental Therapy, L. Hirszfeld Institute of Immunology and Experimental Therapy, Polish Academy of Sciences, R. Weigl Str 12, 53-114 Wroclaw, Poland, Tel: +48 887679779; E-mail: epawlak@iitd.pan.wroc.pl

Rec date: Mar 22, 2014, Acc date: Apr 22, 2014, Pub date: Apr 30, 2014

Copyright: () 2014 Pawlak-Adamska E, et al. This is an open-access article distributed under the terms of the Creative Commons Attribution License, which permits unrestricted use, distribution, and reproduction in any medium, provided the original author and source are credited.

\begin{abstract}
Background: Given the important role of ERCC4 gene in multiple DNA repair systems, we hypothesized that genetic variations within this gene may be a cervical squamous cell carcinoma (CSCC) risk and disease modulatory factor.
\end{abstract}

Methods: In population-based, case-control association study including 143 CSCC patients and 207 healthy women, two ERCC4 tagSNPs were studied.

Results: A significant protective effect against CSCC was observed assuming a dominant model in case of ERCC4rs3136176 ([AA]+[AT]vs. [TT]: $p=0.04, \mathrm{OR}=0.43)$, and genotype [AA] strongly protects against poorly (G3) differentiated CSCC ( $\left.p_{\text {correced }}=0.008, O R=0.15\right)$ and significantly increased the disease remission rate $(p=0.05, O R=0.48)$.

A statistically significant increase frequency of ERCC4rs1799798 [A] allele was seen in patients with well differentiated $(\mathrm{G} 1) \mathrm{CSCC}(\mathrm{p}=0.02$, OR=2.40). Contrary, an opposite trend was observed when $\mathrm{G} 1$ was compared with G2 (moderately differentiated) CSCC $(p=0.06)$. Furthermore, ERCC4rs1799798 [A] allele tended to be increased in patients with carcinoma planoepitheliale keratodes $(C p k)(p=0.07)$.

Haplotype ERCC4rs3136176[A]/ERCC4rs1799798[G] significantly decreased risk of G1 as well as G3 CSCC $(p=0.02, O R=0.50$, and $p=0.017, O R=0.42$, respectively) and only tended to decrease risk of CSCC $(p=0.07, O R=0.758)$ as well as carcinoma planoepitheliale akeratodes $(C p a)(p=0.059,0 R=0.71)$.

In contrast haplotype AA significantly increased risk of G1 CSCC and risk of Cpk $(p=0.01,0 R=2.51, a n d p=0.049$, $\mathrm{OR}=1.96$, respectively), whereas haplotype TG increased risk of G3 CSCC $(p=0.037, \mathrm{OR}=2.17)$.

The overall survival rates showed similar mean survival rates according to patients' genotypes at both studied SNPS.

Conclusion: The above findings consistently suggested that genetic variants in ERCC4 gene may play significant role in CSCC pathophysiology.

Keywords: ERCC4; Genetic variation; Cervical squamous cell carcimona (CSCC); Molecular marker

\section{Introduction}

Cervical squamous cell carcinoma (CSCC) is the third most common cancer diagnosed in women worldwide, with a disproportionate share of the mortality associated with this disease occurring in developing countries. Worldwide, approximately 500,000 new cases are diagnosed each year, with a higher rate of incidence among women of lower socioeconomic status, especially in developing countries [1]. It is well known that cancer progression is associated with persistent high-risk human papillomaviruses (HPV) infection and with deregulated viral gene expression, which leads to excessive cell proliferation, deficient DNA repair, and the accumulation of genetic damage in the infected cell [2]. Dozens of genes are involved in DNA damage repair to maintain genomic stability through different pathways, including direct repair, base excision repair, nucleotide 
Citation: Pawlak-Adamska E, Bartosinska M, Wlodarska-Polinska I, Ignatowicz-Pacyna A, Kornafel J, et al. (2014) Tagging SNPs in the Excision Repair Cross-Complementing Group 4 (ERCC4) Gene Increased Risk of Cervical Squamous Cell Carcinoma (CSCC) and Modulate the Disease Outcome. J Carcinog Mutagen 5: 172. doi:10.4172/2157-2518.1000172

Page 2 of 16

excision repair (NER), mismatch repair and double-strand break repair $[3,4]$.

NER, one of the most versatile DNA repair systems, is responsible for repairing damage caused by many exogenous mutagens. The NER pathway consists of two distinct molecular processes: one - the Global Genome NER (GG-NER), which repairs DNA lesions independently of their localization in the genome, and second - the TranscriptionCoupled NER (TC-NER) pathway, which is activated by lesions in DNA regions involved in transcription. In both cases, the unfolding of the double DNA helix is assured by the helicases XPD (polarity $3^{\prime}-5^{\prime}$ ) and XPB (polarity $5^{\prime}-3^{\prime}$ ) [5]. This process renders the lesion accessible to the endonuclease XPG, which, in conjunction with the helicase $\mathrm{XPA}$, recognizes and verifies the presence of the DNA lesion and subsequently performs the incision of the damaged nucleotide in the $3^{\prime}$ edge of the lesion. In a third critical step, the endonuclease XPF (ERCC4), in association with ERCC1, removes the damaged nucleotide from the 5 ' edge of the damaged chain and deliberates a fragment of 24-32 bases [6,7]. Finally, a complex of DNA polymerases and ligases are recruited in order to perform the synthesis of missing complementary nucleotides and restore normal nucleotide sequence in the damaged chain $[6,7]$.

Besides NER, ERCC4 is also uniquely involved in recombination of DNA inter-strand crosslinking repair (ICL), and takes part in double strand break repair because of its unique function in damage site recognition $[8,9]$.

So, since ERCC4 is involved in both mentioned above repair systems its role in the cancer pathogenesis is postulated. It has been noted that expression level of ERCC4 correlated with risk, progression, cisplatine resistance and clinical course of human cancers, including squamous cell carcinoma of the head and neck (SCCHN) [10-16]. Additionally, it is also hypothesized that XPF has potential to guide next-generation personalized cancer therapy since expression level of XPF in squamous cell carcinoma of the head and neck (SCCHN) tumors correlates with clinical response to DNA damaging agents [10]. Moreover, other study showed that the relative expression level of XPF was the only independent risk factor for SCCHN from simultaneously studied other proteins (i.e. ERCC1, XPA, XPC, XPD, and XPG) and may be a crucial rate-limiting factor in DNA repair [11].

The genetic alterations of this gene may affect the function of their proteins and lead to diseases or cancers. In addition to expression studies, polymorphism analysis of DNA repair genes, including ERCC4 gene, can determine whether germline allelic variants are linked to cancer susceptibility and response to DNA damaging therapy.

The ERCC4 gene is mapped to chromosome 16p13.12, $42 \mathrm{~kb}$ in size, consists of 11 exons and 10 introns (Figure 1) and a total of 580 single nucleotide polymorphisms (SNPs) in human ERCC4 have been reported according to the dbSNP database (http:// www.ncbi.nlm.nih.gov/projects/SNP/snp_ref.cgi? chooseRs=all\&go $=$ Go\&locusId=2072).

\section{chromosome 16p13.2- p.13.13}
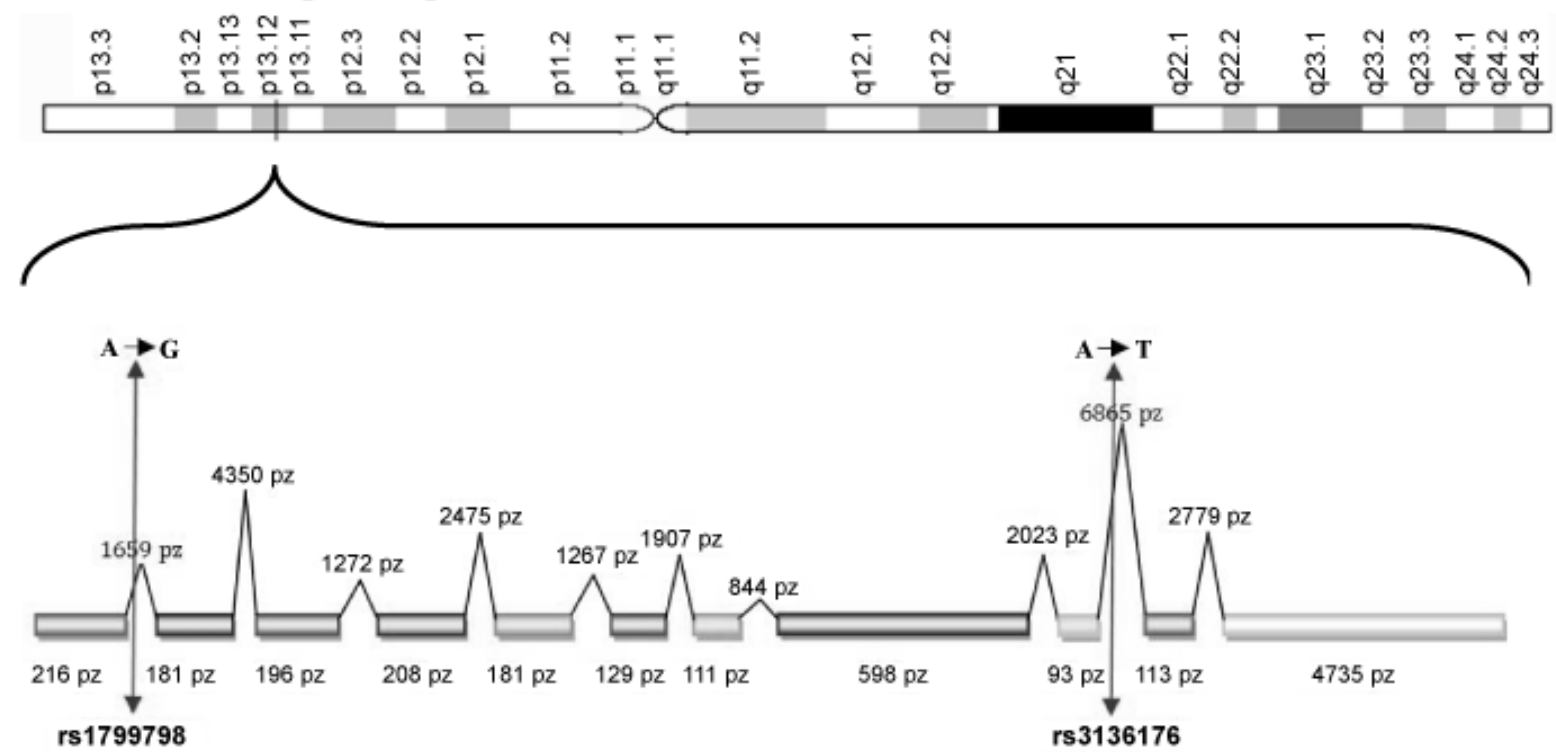

boxes represents exons

Figure 1. Schematic structure of ERCC4 gene with selected tagSNPs location within gene with chromosome location.

So far, genetic variation within ERCC4 gene has been studied in breast [17-24], endometrial [25], lung [26,27], melanoma [28], pancreatic [29], laryngeal [30,31], bladder [32-34], colorectal [35,36] and head and neck [37-39] cancer with the inconsistent results but in cervical squamous cell carcinoma it will be the first study. 
Citation: Pawlak-Adamska E, Bartosinska M, Wlodarska-Polinska I, Ignatowicz-Pacyna A, Kornafel J, et al. (2014) Tagging SNPs in the Excision Repair Cross-Complementing Group 4 (ERCC4) Gene Increased Risk of Cervical Squamous Cell Carcinoma (CSCC) and Modulate the Disease Outcome. J Carcinog Mutagen 5: 172. doi:10.4172/2157-2518.1000172

Page 3 of 16

In this case-control study of cervical squamous cell carcinoma, we examined potential associations between ERCC4 gene, involved in the NER pathway and in ICL, and risk of CSCC, as well as potential modification of disease outcome. Thus, we performed a populationbased case-control study to evaluate the associations between two tagSNPs in ERCC4 gene: rs3136176 and rs1799798 and risk of CSCC in Polish women using data from a case-control study of CSCC, as well as we looking for possible disease-modifying associations.

\section{Subjects and Methods}

\section{Study population}

A total of 143 Caucasian patients with cervical cancer were studied. Patients were treated at Department of Oncology and Gynecological Oncology Clinic, Wroclaw University of Medicine. All cases of cervical cancer were histologically defined as cervical squamous cell carcinoma (CSCC), of which 23 cases were well differentiated (G1), 89 cases moderately (G2), and 16 poorly differentiated (G3) [40]. Stage of the disease was classified according the International Federation of Gynecology and Obstetrics (FIGO) [41]. Classification resulted as follows: stage I: 23 patients; stage II: 49 patients; stage III: 53 patients; and stage IV: 9 patients. In three patients there was no stage description.

Blood samples were taken from patients with CSCC before radiotherapy.

According to tumor stage and extent, radiotherapy alone or combined with concurrent chemotherapy was administered. All patients were treated by external beam radiotherapy (conformal planning); most of them also received brachytherapy (LDR or HDR). A total of 128 patients were treated with curative intent, and 15 received palliative treatment. The patients were evaluated for tumor response: after radical treatment complete regression was achieved in 77 patients and in 18 cases, only partial regression was seen. In 33 patients disease progression was seen.

The control group consisted of 207 healthy, cancer-free women at the time of recruitment. All participants were Polish Caucasians.

Informed consent was obtained from each individual. The study was approved by the local ethics committee.

\section{Genotyping/determination of polymorphisms: Amplification of genomic DNA}

Genomic DNA was prepared from peripheral white blood cells using the QIAamp DNA Blood Mini Kit (Qiagen, Germany) as described previously by Pawlak et al. [42].

Single-nucleotide polymorphisms (SNPs) were selected across preselected cancer-related genes, choosing Tag SNPs with use the LD TAG SNP Selection platform on website of National Institutes of Environmental Health Sciences for Europeans (http:// snpinfo.niehs.nih.gov/snptag.htm).It uses a refined greedy algorithm originally implemented in software TAGster [43] for LD tag SNP selection. LD is measured by $\mathrm{r}^{2}$ or composite linkage disequilibrium (CLD).

The ERCC4rs3136176 and ERCC4rs1799798 SNPs were genotyped with the Allelic discrimination (AD) technique with use the TaqMan SNP Genotyping Assays (made to Order, C__3285107_10 and C_ 7487495_20, respectively). In $\mathrm{AD}$ assay a unique pair of fluorescent dye detectors is used (two TaqMan ${ }^{\circ}$ MGB probes that target a SNP site) and the change in fluorescence of the dyes associated with the probes are measured.

All the assays were validated and predesigned. Reaction components and amplification parameters were based on manufacturer's instructions. The ABI Prism ${ }^{\star} 7300$ (Life Technologies) sequence-detection system was used for amplification for TaqMan SNP genotyping assay plates. SDS version 2.1 (Life Technologies) software was used for data acquisition and analysis. The same software was used for the allelic discrimination-analysis module.

Plate genomic control DNA samples and non-template controls (water) were included for each reaction. The TaqMan SNP genotyping assay was controlled ( $25 \%$ of randomly chosen samples from both groups) to check for genotyping accuracy. Identical genotypes were identified in all repeated samples. The ID sample subjects during genotyping were not known.

\section{Statistical analyses}

Evaluation of the Hardy-Weinberg equilibrium (HWE) was performed for the whole studied groups by comparing the observed and expected frequencies of genotypes using $\chi^{2}$ analysis. The $\chi^{2}$ test was used to compare categorical data between patients with CSCC and controls. When at least one cell value was not more than 5, the Yates' correction was applied to the $\chi^{2}$-value. Differences were considered as statistically significant if the $\mathrm{p}$ value was $<0.05$.

Because of the multiple comparisons of the allele, genotype, and haplotype frequencies, Bonferroni multiple adjustments were employed to the level of significance. The haplotype frequencies for pairs of alleles were estimated using the SHEsis program (http:// analysis.bio-x.cn/myAnalysis.php) [44,45].

The log-rank test was used to assess the effect of each polymorphic variable on disease-free survival from the date of starting therapy to the date of last follow-up. Analysis was cured on the group of patients radically treated with the stage of the disease II and III. A total of 70 patients were assessed in this analysis; 15 manifested as having welldifferentiated tumors (G1), 48 moderately differentiated (G2), and seven poorly differentiated CSCC (G3). Survival curves were estimated by the Kaplan-Meier method and a two-sided $p$ value of $<0.05$ from a log-rank test was considered as statistically significant difference. Logrank tests were performed with STATISTICA10.0 software (StatSoft, Crakow, Poland).

\section{Results}

All ERCC4 genotype distributions in the controls as well as in CSCC patients were consistent with those expected from the HardyWeinberg equilibrium model (all $\mathrm{p}>0.05$, Table 1 ).

\section{SNPs in the ERCC4 gene}

Although no association was found when comparing the genotype in both studied polymorphic sites, a formally significant protective effect was observed assuming a dominant model in case of ERCC4rs3136176 SNP ([AA] + [AT] vs. [TT]: $\mathrm{p}=0.04, \mathrm{OR}=0.43,95 \%$ CI:0.19 - 0.99, Table 1). Moreover, when the rs3136176 [AA] homozygote was used as the reference group, [TT] genotype tended to increased risk of disease ( $\mathrm{p}=0.06, \mathrm{OR}=2.23,95 \% \mathrm{CI}$ : $0.95-5.22$, Table $1)$. 
Citation: Pawlak-Adamska E, Bartosinska M, Wlodarska-Polinska I, Ignatowicz-Pacyna A, Kornafel J, et al. (2014) Tagging SNPs in the Excision Repair Cross-Complementing Group 4 (ERCC4) Gene Increased Risk of Cervical Squamous Cell Carcinoma (CSCC) and Modulate the Disease Outcome. J Carcinog Mutagen 5: 172. doi:10.4172/2157-2518.1000172

\begin{tabular}{|c|c|c|c|c|c|c|}
\hline & $\begin{array}{l}\text { CSCC patients } \\
n=143 \\
n(\%)\end{array}$ & \multicolumn{2}{|c|}{$\begin{array}{l}\text { Control group } \\
n=207 \\
n(\%)\end{array}$} & $\mathrm{p}$ & OR & $95 \% \mathrm{Cl}$ \\
\hline \multicolumn{7}{|l|}{ rs3136176 } \\
\hline \multicolumn{7}{|l|}{ Genotype } \\
\hline$[\mathrm{AA}]$ & $78(54.5)$ & \multicolumn{2}{|l|}{$116(56.0)$} & \multicolumn{3}{|c|}{ referent } \\
\hline $\begin{array}{l}{[\mathrm{AT}]} \\
{[\mathrm{TT}]}\end{array}$ & $\begin{array}{l}50(35.0) \\
15(10.5)\end{array}$ & \multicolumn{2}{|l|}{$\begin{array}{l}81(39.2) \\
10(4.8)\end{array}$} & $\begin{array}{l}0.71 \\
0.06\end{array}$ & $\begin{array}{l}0.92 \\
2.23\end{array}$ & $\begin{array}{l}0.58-1.45 \\
0.95-5.22\end{array}$ \\
\hline \multicolumn{7}{|l|}{ Allele } \\
\hline $\begin{array}{l}{[\mathrm{A}]} \\
{[\mathrm{T}]}\end{array}$ & $\begin{array}{l}206(72.0) \\
80(28.0)\end{array}$ & \multicolumn{2}{|l|}{$\begin{array}{l}313(75.6) \\
101(24.4)\end{array}$} & 0.29 & $\begin{array}{l}0.83 \\
1.20\end{array}$ & $\begin{array}{l}0.59-1.17 \\
0.86-1.69\end{array}$ \\
\hline \multicolumn{7}{|l|}{ Dominant model } \\
\hline$[\mathrm{AA}]+[\mathrm{AT}] \mathrm{vs} .[\mathrm{TT}]$ & $\begin{array}{l}128(89.5) \\
15(10.5)\end{array}$ & \multicolumn{2}{|l|}{$\begin{array}{l}197(95.2) \\
10(4.8)\end{array}$} & 0.04 & $\begin{array}{l}0.43 \\
2.31\end{array}$ & $\begin{array}{l}0.19-0.99 \\
1.01-5.30\end{array}$ \\
\hline \multicolumn{7}{|l|}{ Recessive model } \\
\hline$[T T]+[A T]$ vs. $[A A]$ & $\begin{array}{l}65(45.5) \\
78(54.5)\end{array}$ & \multicolumn{2}{|l|}{$\begin{array}{l}91(44.0) \\
116(56.0)\end{array}$} & 0.78 & $\begin{array}{l}1.06 \\
0.94\end{array}$ & $\begin{array}{l}0.69-1.63 \\
0.61-1.45\end{array}$ \\
\hline \multicolumn{7}{|l|}{ rs1799798 } \\
\hline \multicolumn{7}{|l|}{ Genotype } \\
\hline [GG] & $107(74.8)$ & \multirow{2}{*}{\multicolumn{2}{|c|}{$\begin{array}{l}162(78.3) \\
42(20.3) \\
3(1.4)\end{array}$}} & \multicolumn{3}{|c|}{ referent } \\
\hline $\begin{array}{l}{[\mathrm{GA}]} \\
{[\mathrm{AA}]}\end{array}$ & $\begin{array}{l}32(22.4) \\
4(2.8)\end{array}$ & & & $\begin{array}{l}0.59 \\
0.59^{*}\end{array}$ & $\begin{array}{l}1.15 \\
2.02\end{array}$ & $\begin{array}{l}0.69-1.94 \\
0.44-9.20\end{array}$ \\
\hline \multicolumn{7}{|l|}{ Allele } \\
\hline $\begin{array}{l}{[G]} \\
{[A]}\end{array}$ & $\begin{array}{l}246(86.0) \\
40(14.0)\end{array}$ & \multicolumn{2}{|l|}{$\begin{array}{l}366(88.4) \\
48(11.6)\end{array}$} & 0.35 & $\begin{array}{l}0.81 \\
1.24\end{array}$ & $\begin{array}{l}0.51-1.26 \\
0.79-1.94\end{array}$ \\
\hline \multicolumn{7}{|l|}{ Dominant model } \\
\hline$[G G]+[G A]$ vs. $[A A]$ & $\begin{array}{l}137(97.3) \\
4(2.8)\end{array}$ & \multicolumn{2}{|l|}{$\begin{array}{l}207(98.6) \\
3(1.4)\end{array}$} & 0.59 & $\begin{array}{l}0.50 \\
2.01\end{array}$ & $\begin{array}{l}0.11-2.25 \\
0.44-9.14\end{array}$ \\
\hline \multicolumn{7}{|l|}{ Recessive model } \\
\hline$[A A]+[G A]$ vs. $[G G]$ & $\begin{array}{l}36(25.2) \\
107(74.8)\end{array}$ & \multicolumn{2}{|l|}{$\begin{array}{l}45(21.7) \\
162(78.3)\end{array}$} & 0.45 & $\begin{array}{l}1.21 \\
0.83\end{array}$ & $\begin{array}{l}0.73-2.00 \\
0.50-1.36\end{array}$ \\
\hline \multicolumn{7}{|c|}{$\begin{array}{l}\text { OR - Odds Ratio } \\
95 \% \mathrm{Cl} \text { - } 95 \% \text { Confidence Intervals } \\
\wedge \text { - p-value after Bonferroni correction } \\
\text { * - p-value after Yate's correction } \\
\text { \#- global p-value for genotype }\end{array}$} \\
\hline \multicolumn{3}{|l|}{ rs3136176 } & \multicolumn{4}{|l|}{ rs1799798 } \\
\hline \multicolumn{3}{|c|}{$\begin{array}{l}1-X^{2}=4.217333, d f=2, p=0.121508 \\
H W E_{C S C C} \text { patients: } X^{2}=2.502273, p=0.113745\end{array}$} & \multicolumn{4}{|c|}{$\begin{array}{l}{ }^{2}-x^{2}=1.072568, d f=2, p=584951 \\
H W E_{C S C C} \text { patients: } x^{2}=0.699073, p=0.403135\end{array}$} \\
\hline
\end{tabular}


Citation: Pawlak-Adamska E, Bartosinska M, Wlodarska-Polinska I, Ignatowicz-Pacyna A, Kornafel J, et al. (2014) Tagging SNPs in the Excision Repair Cross-Complementing Group 4 (ERCC4) Gene Increased Risk of Cervical Squamous Cell Carcinoma (CSCC) and Modulate the Disease Outcome. J Carcinog Mutagen 5: 172. doi:10.4172/2157-2518.1000172

Page 5 of 16

HWE controls: $X^{2}=0.764352, p=0.382012$

$H W E_{\text {controls }}: X^{2}=0.021731, p=0.882812$

Table 1: ERCC4rs3136176 and ERCC4rs1799798 genotype, allele and phenotype frequencies in cervical squamous cell carcinoma (CSCC) patients and controls.

In our group of healthy cancer-free women and CSCC patients both studied SNPs were in tight LD (control group: $\mathrm{D}^{\prime}=0.820$, CSCC patients: $D^{\prime}=0.998$ ).

in the controls (the global $\mathrm{p}$ value after the Bonferroni correction was 0.18 ) notwithstanding a trend toward decreased frequency of ERCC4rs3136176[A]/ERCC4rs1799798[G] haplotype was noted in CSCC patients as compared with healthy women $\left(\mathrm{p}=0.068, \chi^{2}=3.314\right.$,

Haplotype evaluation of studied polymorphic sites was performed and the frequencies of the haplotypes did not differ in the patients and

$\mathrm{OR}=0.750,95 \%$ CI: $0.550-1.023$, Table 2).

\begin{tabular}{|c|c|c|c|c|c|c|}
\hline & CSCC patients & Control group & $x^{2}$ & $\mathbf{p}$ & OR & $95 \% \mathrm{Cl}$ \\
\hline \multicolumn{7}{|c|}{ ERCC4rs3136176 / ERCC4rs1799798 } \\
\hline A A & $39.98(0.140)$ & $45.89(0.111)$ & 1.262 & 0.261335 & 1.296 & $0.823-2.041$ \\
\hline$A G$ & $166.02(0.580)$ & $267.11(0.645)$ & 3.314 & 0.068698 & 0.750 & $0.550-1.023$ \\
\hline T G & $79.98(0.280)$ & $98.89(0.239)$ & 1.388 & 0.238713 & 1.229 & $0.872-1.732$ \\
\hline TA & $0.02(0.000)$ & $2.11(0.005)$ & - & - & - & - \\
\hline
\end{tabular}

Table 2. Haplotype (ERCC4rs3136176 / ERCC4rs1799798) frequencies in cervical squamous cell carcinoma (CSCC) patients and controls.

\section{ERCC4 gene polymorphisms and clinical data in CSCC}

The features of the ERCC4 genes polymorphisms according to the patients clinicopathologic characteristics, namely, the grade, stage of disease, response to treatment and progression-free survival was analyzed.

The association between ERCC4 SNPs and susceptibility to CSCC varied in relation to histologic grade of tumor. The distribution of ERCC4rs3136176 genotypes significantly varies between CSCC patients and healthy women ( $p_{\text {after Bonferroni correction }}=0.01, \chi^{2}=$ 10.269320, Table 3). Particularly, when the rs3136176[AA] homozygote was used as the reference group, the [TT] genotype was associated with a significantly increased risk of poorly (G3) differentiated CSCC ( $\mathrm{p}_{\text {after Yate's correction }}=0.01, \mathrm{OR}=6.57,95 \%$ CI:1.64 - 26.33, Table 3). In a dominant model ([AA] + [AT] vs. [TT]) this association was much stronger ( $p_{\text {after Yate's correction }}=0.008, \mathrm{OR}=6.57$, 95\% CI: 1.79 - 24.01, Table 3).

\begin{tabular}{|c|c|c|c|c|c|c|c|c|c|}
\hline & $\begin{array}{l}\text { Control group } \\
(\mathrm{n}=207) \\
\mathrm{n}(\%)\end{array}$ & $\begin{array}{l}\text { G1 } \\
(\mathrm{n}=23) \\
\mathrm{n}(\%)\end{array}$ & $\begin{array}{l}\text { G2 } \\
(\mathrm{n}=89) \\
\mathrm{n}(\%)\end{array}$ & $\begin{array}{l}\text { G3 } \\
(\mathrm{n}=16) \\
\mathrm{n}(\%)\end{array}$ & & $\mathbf{p}_{\text {total }}$ & p & OR & $95 \% \mathrm{Cl}$ \\
\hline \multicolumn{10}{|c|}{ rs3136176 } \\
\hline \multicolumn{10}{|c|}{ Genotype } \\
\hline$[\mathrm{AA}]$ & $116(56.0)$ & $13(56.5)$ & $47(52.8)$ & $7(43.8)$ & & \multirow{3}{*}{$\begin{array}{l}\mathrm{ns}^{1} \\
\mathrm{~ns}^{2} \\
0.01^{3} \\
\mathrm{~ns}^{4} \\
\mathrm{~ns}^{5} \\
\mathrm{~ns}^{6}\end{array}$} & \multicolumn{3}{|c|}{ referent } \\
\hline [AT] & 81 (39.1) & $7(30.4)$ & $34(38.2)$ & $5(31.2)$ & $\begin{array}{l}\mathrm{G} 1 \text { vs. } \mathrm{G} 2 \\
\mathrm{G} 1 \text { vs. } \mathrm{G} 3 \\
\mathrm{G} 2 \text { vs. } \mathrm{G} 3 \\
\mathrm{G} 1 \text { vs. control } \\
\mathrm{G} 2 \text { vs. control } \\
\mathrm{G} 3 \text { vs. control }\end{array}$ & & $\begin{array}{l}0.57 \\
0.71 \\
0.77 \\
0.57 \\
1.00 \\
0.77\end{array}$ & $\begin{array}{l}1.34 \\
1.33 \\
0.99 \\
0.76 \\
0.99 \\
1.00\end{array}$ & $\begin{array}{l}0.49-3.72 \\
0.31-5.77 \\
0.29-3.38 \\
0.29-1.98 \\
0.58-1.67 \\
0.31-3.26\end{array}$ \\
\hline [TT] & $10(4.8)$ & $3(13.1)$ & $8(9.0)$ & $4(25.0)$ & $\begin{array}{l}\mathrm{G} 1 \text { vs. } \mathrm{G} 2 \\
\mathrm{G} 1 \text { vs. } \mathrm{G} 3 \\
\mathrm{G} 2 \text { vs. } \mathrm{G} 3 \\
\mathrm{G} 1 \text { vs. control }\end{array}$ & & $\begin{array}{l}1.00 \\
0.56 \\
0.20 \\
0.35\end{array}$ & $\begin{array}{l}0.74 \\
2.48 \\
3.36 \\
2.65\end{array}$ & $\begin{array}{l}0.17-3.18 \\
0.43-14.34 \\
0.80-14.16 \\
0.65-10.89\end{array}$ \\
\hline
\end{tabular}


Citation: Pawlak-Adamska E, Bartosinska M, Wlodarska-Polinska I, Ignatowicz-Pacyna A, Kornafel J, et al. (2014) Tagging SNPs in the Excision Repair Cross-Complementing Group 4 (ERCC4) Gene Increased Risk of Cervical Squamous Cell Carcinoma (CSCC) and Modulate the Disease Outcome. J Carcinog Mutagen 5: 172. doi:10.4172/2157-2518.1000172

Page 6 of 16

\begin{tabular}{|c|c|c|c|c|c|c|c|c|c|}
\hline & & & & & & $\begin{array}{l}\text { G2 vs. control } \\
\text { G3 vs. control }\end{array}$ & $\begin{array}{l}0.18 \\
0.01^{*}\end{array}$ & $\begin{array}{l}1.96 \\
6.57\end{array}$ & $\begin{array}{l}0.73-5.27 \\
1.64-26.33\end{array}$ \\
\hline \multicolumn{10}{|l|}{ Allele } \\
\hline$[\mathrm{A}]$ & $313(75.6)$ & $33(71.7)$ & $128(71.9)$ & \multicolumn{2}{|c|}{$19(59.4)$} & $\begin{array}{l}\text { G1 vs. } G 2 \\
\text { G1 vs. G3 } \\
\text { G2 vs. G3 } \\
\text { G1 vs. control } \\
\text { G2 vs. control } \\
\text { G3 vs. control }\end{array}$ & $\begin{array}{l}1.00 \\
0.25 \\
0.15 \\
0.56 \\
0.34 \\
0.04\end{array}$ & $\begin{array}{l}1.01 \\
0.58 \\
0.57 \\
0.82 \\
0.83 \\
0.47\end{array}$ & $\begin{array}{l}0.49-2.07 \\
0.22-1.49 \\
0.26-1.24 \\
0.42-1.62 \\
0.56-1.23 \\
0.23-0.99\end{array}$ \\
\hline$[\mathrm{T}]$ & $101(24.4)$ & $13(28.3)$ & $50(28.1)$ & \multicolumn{2}{|c|}{$13(40.6)$} & $\begin{array}{l}\mathrm{G} 1 \text { vs. } \mathrm{G} 2 \\
\mathrm{G} 1 \text { vs. } \mathrm{G} 3 \\
\mathrm{G} 2 \text { vs. } \mathrm{G} 3 \\
\mathrm{G} 1 \text { vs. control } \\
\mathrm{G} 2 \text { vs. control } \\
\mathrm{G} 3 \text { vs. control }\end{array}$ & $\begin{array}{l}1.00 \\
0.25 \\
0.15 \\
0.56 \\
0.34 \\
0.04\end{array}$ & $\begin{array}{l}0.99 \\
1.74 \\
1.75 \\
1.22 \\
1.21 \\
2.12\end{array}$ & $\begin{array}{l}0.48-2.04 \\
0.67-4.51 \\
0.81-3.81 \\
0.62-2.41 \\
0.81-1.80 \\
1.01-4.45\end{array}$ \\
\hline \multicolumn{10}{|c|}{ Dominant model } \\
\hline \multirow[t]{2}{*}{$\begin{array}{l}{[\mathrm{AA}]+[\mathrm{AT}]} \\
\text { vs. } \\
{[\mathrm{TT}]}\end{array}$} & $197(95.2)$ & $20(84.9)$ & $81(91.0)$ & \multicolumn{2}{|c|}{$12(75.0)$} & $\begin{array}{l}\mathrm{G} 1 \text { vs. } \mathrm{G} 2 \\
\mathrm{G} 1 \text { vs. } \mathrm{G} 3 \\
\mathrm{G} 2 \text { vs. } \mathrm{G} 3 \\
\mathrm{G} 1 \text { vs. control } \\
\mathrm{G} 2 \text { vs. control } \\
\mathrm{G} 3 \text { vs. control }\end{array}$ & $\begin{array}{l}0.85^{*} \\
0.59^{*} \\
0.15^{*} \\
0.25^{*} \\
0.17 \\
0.008^{*}\end{array}$ & $\begin{array}{l}1.52 \\
2.22 \\
0.30 \\
0.34 \\
0.51 \\
0.15\end{array}$ & $\begin{array}{l}0.37-6.25 \\
0.42-11.68 \\
0.08-1.14 \\
0.09-1.33 \\
0.20-1.35 \\
0.04-0.56\end{array}$ \\
\hline & $10(4.8)$ & $3(13.1)$ & $8(9.0)$ & $\begin{array}{l}4 \\
(25.0 \\
)\end{array}$ & $\begin{array}{l}\text { G1 vs. } \\
\text { G2 } \\
\text { G1 vs. } \\
\text { G3 } \\
\text { G2 vs. } \\
\text { G3 } \\
\text { G1 vs. } \\
\text { control } \\
\text { G2 vs. } \\
\text { control } \\
\text { G3 vs. } \\
\text { control }\end{array}$ & $\begin{array}{l}0.85^{*} \\
0.59^{*} \\
0.15^{\star} \\
0.25^{\star} \\
0.17 \\
0.008^{*}\end{array}$ & $\begin{array}{l}0.66 \\
0.45 \\
3.38 \\
2.96 \\
1.95 \\
6.57\end{array}$ & $\begin{array}{l}0.16- \\
2.71 \\
0.09 \quad- \\
2.37 \\
0.88 \quad- \\
12.95 \\
0.75- \\
11.63 \\
0.74 \quad- \\
5.11 \\
1.79- \\
24.01\end{array}$ & \\
\hline \multicolumn{10}{|c|}{ Recessive model } \\
\hline \multirow[t]{2}{*}{$\begin{array}{l}{[\mathrm{TT}]+[\mathrm{AT}]} \\
\text { vs. } \\
{[\mathrm{AA}]}\end{array}$} & $91(44.0)$ & $10(43.5)$ & $42(47.2)$ & \multicolumn{2}{|c|}{$9(56.2)$} & $\begin{array}{l}\mathrm{G} 1 \text { vs. } \mathrm{G} 2 \\
\mathrm{G} 1 \text { vs. } \mathrm{G} 3 \\
\mathrm{G} 2 \text { vs. } \mathrm{G} 3 \\
\mathrm{G} 1 \text { vs. control } \\
\mathrm{G} 2 \text { vs. control } \\
\mathrm{G} 3 \text { vs. control }\end{array}$ & $\begin{array}{l}0.75 \\
0.43 \\
0.50 \\
1.00 \\
0.61 \\
0.34\end{array}$ & $\begin{array}{l}1.16 \\
1.67 \\
1.44 \\
0.98 \\
1.14 \\
1.64\end{array}$ & $\begin{array}{l}0.46-2.93 \\
0.46-6.05 \\
0.49-4.20 \\
0.41-2.34 \\
0.69-1.88 \\
0.59-4.57\end{array}$ \\
\hline & $116(56.0)$ & $13(56.5)$ & $47(52.8)$ & $\begin{array}{l}7 \\
(43.8 \\
)\end{array}$ & $\begin{array}{l}\text { G1 vs. } \\
\text { G2 } \\
\text { G1 vs. } \\
\text { G3 } \\
\text { G2 vs. } \\
\text { G3 } \\
\text { G1 vs. } \\
\text { control }\end{array}$ & $\begin{array}{l}0.75 \\
0.43 \\
0.50 \\
1.00 \\
0.61 \\
0.34\end{array}$ & $\begin{array}{l}0.86 \\
0.60 \\
0.70 \\
1.02 \\
0.88 \\
0.61\end{array}$ & $\begin{array}{ll}0.34 & - \\
2.17 & \\
0.17 & - \\
2.17 & \\
0.24 & - \\
2.03 & \\
0.43 & - \\
2.43 & \end{array}$ & \\
\hline
\end{tabular}


Citation: Pawlak-Adamska E, Bartosinska M, Wlodarska-Polinska I, Ignatowicz-Pacyna A, Kornafel J, et al. (2014) Tagging SNPs in the Excision Repair Cross-Complementing Group 4 (ERCC4) Gene Increased Risk of Cervical Squamous Cell Carcinoma (CSCC) and Modulate the Disease Outcome. J Carcinog Mutagen 5: 172. doi:10.4172/2157-2518.1000172

Page 7 of 16

\begin{tabular}{|c|c|c|c|c|c|c|c|c|c|c|}
\hline & & & & & $\begin{array}{l}\text { G2 vs. } \\
\text { control } \\
\text { G3 vs. } \\
\text { control }\end{array}$ & & & & $\begin{array}{l}0.53- \\
1.45 \\
0.22- \\
1.70\end{array}$ & \\
\hline \multicolumn{11}{|l|}{ rs1799798 } \\
\hline \multicolumn{11}{|l|}{ Genotype } \\
\hline [GG] & $162(78.3)$ & $14(60.9)$ & 68 (76.4) & \multicolumn{2}{|c|}{$11(68.8)$} & & 0.067 & \multicolumn{3}{|c|}{ referent } \\
\hline [GA] & $42(20.3)$ & $7(30.4)$ & $19(21.3)$ & \multicolumn{2}{|c|}{$5(31.2)$} & $\begin{array}{l}\mathrm{G} 1 \text { vs. } \mathrm{G} 2 \\
\mathrm{G} 1 \text { vs. } \mathrm{G} 3 \\
\mathrm{G} 2 \text { vs. } \mathrm{G} 3 \\
\mathrm{G} 1 \text { vs. control } \\
\mathrm{G} 2 \text { vs. control } \\
\mathrm{G} 3 \text { vs. control }\end{array}$ & $\begin{array}{l}\mathrm{ns}^{9} \\
\mathrm{~ns}^{10} \\
\mathrm{~ns}^{11} \\
\mathrm{~ns}^{12}\end{array}$ & $\begin{array}{l}0.27 \\
0.83^{*} \\
0.62^{*} \\
0.18 \\
0.81 \\
0.49^{\star}\end{array}$ & $\begin{array}{l}0.56 \\
1.10 \\
1.63 \\
1.93 \\
1.08 \\
1.75\end{array}$ & $\begin{array}{l}0.20-1.58 \\
0.27-4.43 \\
0.50-5.26 \\
0.73-5.08 \\
0.59-1.99 \\
0.58-5.32\end{array}$ \\
\hline$[\mathrm{AA}]$ & $3(1.4)$ & $2(8.7)$ & $2(2.2)$ & \multicolumn{2}{|c|}{$0(0.0)$} & $\begin{array}{l}\mathrm{G} 1 \text { vs. } \mathrm{G} 2 \\
\mathrm{G} 1 \text { vs. } \mathrm{G} 3 \\
\mathrm{G} 2 \text { vs. } \mathrm{G} 3 \\
\mathrm{G} 1 \text { vs. control } \\
\mathrm{G} 2 \text { vs. control } \\
\mathrm{G} 3 \text { vs. control }\end{array}$ & & $\begin{array}{l}0.32^{*} \\
0.64^{*} \\
0.63^{*} \\
0.09^{*} \\
1.00^{*} \\
0.45^{*}\end{array}$ & $\begin{array}{l}0.21 \\
- \\
- \\
7.71 \\
1.59 \\
-\end{array}$ & $\begin{array}{l}0.03-1.59 \\
- \\
- \\
1.19-50.09 \\
0.26-9.72 \\
-\end{array}$ \\
\hline \multicolumn{11}{|l|}{ Allele } \\
\hline [G] & $366(88.4)$ & $35(76.1)$ & $155(90.1)$ & \multicolumn{2}{|c|}{$27(84.4)$} & $\begin{array}{l}\mathrm{G} 1 \text { vs. } \mathrm{G} 2 \\
\mathrm{G} 1 \text { vs. } \mathrm{G} 3 \\
\mathrm{G} 2 \text { vs. } \mathrm{G} 3 \\
\mathrm{G} 1 \text { vs. control } \\
\mathrm{G} 2 \text { vs. control } \\
\mathrm{G} 3 \text { vs. control }\end{array}$ & & $\begin{array}{l}0.06 \\
0.54^{*} \\
1.00^{*} \\
0.02 \\
0.65 \\
0.69^{*}\end{array}$ & $\begin{array}{l}2.12 \\
1.70 \\
0.80 \\
0.42 \\
1.13 \\
0.71\end{array}$ & $\begin{array}{l}0.95-4.75 \\
0.53-5.47 \\
0.28-2.29 \\
0.20-0.88 \\
0.67-1.93 \\
0.26-1.93\end{array}$ \\
\hline$[A]$ & $48(11.6)$ & $11(23.9)$ & $23(9.9)$ & \multicolumn{2}{|c|}{$5(15.6)$} & $\begin{array}{l}\mathrm{G} 1 \text { vs. } \mathrm{G} 2 \\
\mathrm{G} 1 \text { vs. } \mathrm{G} 3 \\
\mathrm{G} 2 \text { vs. } \mathrm{G} 3 \\
\mathrm{G} 1 \text { vs. control } \\
\mathrm{G} 2 \text { vs. control } \\
\mathrm{G} 3 \text { vs. control }\end{array}$ & & $\begin{array}{l}0.06 \\
0.54^{*} \\
1.00^{*} \\
0.02 \\
0.65 \\
0.69^{*}\end{array}$ & $\begin{array}{l}0.47 \\
0.59 \\
1.25 \\
2.40 \\
0.88 \\
1.41\end{array}$ & $\begin{array}{l}0.21-1.06 \\
0.18-1.90 \\
0.44-3.57 \\
1.14-5.03 \\
0.52-1.50 \\
0.52-3.84\end{array}$ \\
\hline \multicolumn{11}{|c|}{ Dominant model } \\
\hline \multirow[t]{2}{*}{$\begin{array}{l}{[G G]+[G A]} \\
\text { vs. } \\
{[A A]}\end{array}$} & $204(98.6)$ & $21(91.3)$ & $87(97.8)$ & \multicolumn{2}{|c|}{$16(100.0)$} & $\begin{array}{l}\mathrm{G} 1 \text { vs. } \mathrm{G} 2 \\
\mathrm{G} 1 \text { vs. } \mathrm{G} 3 \\
\mathrm{G} 2 \text { vs. } \mathrm{G} 3 \\
\mathrm{G} 1 \text { vs. control } \\
\mathrm{G} 2 \text { vs. control } \\
\mathrm{G} 3 \text { vs. control }\end{array}$ & & $\begin{array}{l}0.39^{*} \\
0.22^{*} \\
0.15^{\star} \\
0.13^{*} \\
1.00^{\star} \\
0.52^{\star}\end{array}$ & $\begin{array}{l}4.14 \\
- \\
- \\
0.15 \\
0.64 \\
-\end{array}$ & $\begin{array}{l}0.55-31.14 \\
- \\
- \\
0.02-0.98 \\
0.11-3.90 \\
-\end{array}$ \\
\hline & $3(1.4)$ & $2(8.7)$ & $2(2.2)$ & $\begin{array}{l}0 \\
(0.0)\end{array}$ & $\begin{array}{l}\text { G1 vs. } \\
\text { G2 } \\
\text { G1 vs. } \\
\text { G3 } \\
\text { G2 vs. } \\
\text { G3 } \\
\text { G1 vs. } \\
\text { control }\end{array}$ & $\begin{array}{l}0.39^{\star} \\
0.22^{\star} \\
0.15^{\star} \\
0.13^{\star} \\
1.00^{\star} \\
0.52^{\star}\end{array}$ & & $\begin{array}{l}0.24 \\
- \\
- \\
6.48 \\
1.56 \\
-\end{array}$ & $\begin{array}{l}0.03- \\
1.81 \\
- \\
- \\
1.02 \quad- \\
40.97 \\
0.26- \\
9.52\end{array}$ & \\
\hline
\end{tabular}


Citation: Pawlak-Adamska E, Bartosinska M, Wlodarska-Polinska I, Ignatowicz-Pacyna A, Kornafel J, et al. (2014) Tagging SNPs in the Excision Repair Cross-Complementing Group 4 (ERCC4) Gene Increased Risk of Cervical Squamous Cell Carcinoma (CSCC) and Modulate the Disease Outcome. J Carcinog Mutagen 5: 172. doi:10.4172/2157-2518.1000172

Page 8 of 16

\begin{tabular}{|c|c|c|c|c|c|c|c|c|c|}
\hline & & & & & $\begin{array}{l}\text { G2 vs. } \\
\text { control } \\
\text { G3 vs. } \\
\text { control }\end{array}$ & & & - & \\
\hline \multicolumn{10}{|c|}{ Recessive model } \\
\hline \multirow{13}{*}{$\begin{array}{l}{[A A]+[G A]} \\
\text { vs. } \\
{[G G]}\end{array}$} & $45(21.7)$ & $9(39.1)$ & $21(23.6)$ & \multirow{6}{*}{\multicolumn{2}{|c|}{$5(31.2)$}} & G1 vs. G2 & 0.13 & 0.48 & $0.18-1.27$ \\
\hline & & & & & & G1 vs. G3 & $0.87^{*}$ & 0.71 & $0.18-2.72$ \\
\hline & & & & & & G2 vs. G3 & $0.73^{*}$ & 1.47 & $0.46-4.72$ \\
\hline & & & & & & G1 vs. control & 0.06 & 2.31 & $0.94-5.69$ \\
\hline & & & & & & G2 vs. control & 0.72 & 1.11 & $0.62-2.01$ \\
\hline & & & & & & G3 vs. control & 0.57 & 1.64 & $0.54-4.95$ \\
\hline & $162(78.3)$ & $14(60.9)$ & $68(76.4)$ & $\begin{array}{l}11 \\
(68.8\end{array}$ & $\begin{array}{l}\text { G1 vs. } \\
\text { G2 }\end{array}$ & $\begin{array}{l}0.13 \\
0.87^{\star}\end{array}$ & $\begin{array}{l}2.08 \\
1.41\end{array}$ & $\begin{array}{ll}0.79 & - \\
5.49 & \end{array}$ & \\
\hline & & & & & $\begin{array}{l}\text { G1 vs. } \\
\text { G3 }\end{array}$ & $0.73^{*}$ & 0.68 & $\begin{array}{l}0.37 \\
5.45\end{array}-$ & \\
\hline & & & & & $\mathrm{G} 2$ vs. & 0.06 & 0.43 & $0.21-$ & \\
\hline & & & & & G3 & 0.72 & 0.90 & 2.18 & \\
\hline & & & & & $\begin{array}{l}\text { G1 vs. } \\
\text { control }\end{array}$ & 0.57 & 0.61 & $\begin{array}{l}0.18- \\
1.06\end{array}$ & \\
\hline & & & & & $\begin{array}{l}\text { G2 vs. } \\
\text { control }\end{array}$ & & & $\begin{array}{l}0.50- \\
1.62\end{array}$ & \\
\hline & & & & & $\begin{array}{l}\text { G3 vs. } \\
\text { control }\end{array}$ & & & $\begin{array}{l}0.20 \\
1.85\end{array}-$ & \\
\hline \multicolumn{10}{|c|}{${ }^{\wedge}-\mathrm{p}$-value after Bonferroni correction } \\
\hline \multicolumn{10}{|c|}{ * - p-value after Yate's correction } \\
\hline \multicolumn{10}{|c|}{ \#- global p-value for genotype } \\
\hline \multicolumn{10}{|c|}{ Bold indicates a statistically significant differences } \\
\hline \multicolumn{5}{|l|}{ rs3136176 } & \multicolumn{5}{|c|}{ rs1799798 } \\
\hline \multicolumn{5}{|c|}{$1-\mathrm{G} 1$ vs. controls: $\mathrm{x}^{2}=2.880038, \mathrm{df}=2, \mathrm{p}=0.236923$} & \multicolumn{5}{|c|}{${ }^{7}-\mathrm{G} 1$ vs. controls: $\mathrm{x}^{2}=6.818182, \mathrm{df}=2, \mathrm{p}=0.033148$} \\
\hline \multicolumn{5}{|c|}{$2-G 2$ vs. controls: $x^{2}=1.901089, d f=2, p=0.386531$} & \multicolumn{5}{|c|}{${ }^{8}-\mathrm{G} 2$ vs. controls: $x^{2}=0.296027, d f=2, p=0.862423$} \\
\hline \multicolumn{5}{|c|}{$3-\mathrm{G} 3$ vs. controls: $x^{2}=10.269320, d f=2, p=0.005920$} & \multicolumn{5}{|c|}{${ }^{9}-\mathrm{G} 3$ vs. controls: $x^{2}=1.251555, d f=2, p=0.534887$} \\
\hline \multicolumn{5}{|c|}{$4-G 1$ vs. $G 3: x^{2}=1.053727, d f=2, p=0.590487$} & \multicolumn{5}{|c|}{$10-G 1$ vs. $G 2: x^{2}=3.380476, d f=2, p=0.184581$} \\
\hline \multicolumn{5}{|c|}{$5-\mathrm{G} 1$ vs. $\mathrm{G} 3: \mathrm{x}^{2}=1.053727, \mathrm{df}=2, p=0.590487$} & \multicolumn{5}{|c|}{$11-G 1$ vs. $G 3: x^{2}=1.484755, d f=2, p=0.476033$} \\
\hline \multicolumn{5}{|c|}{$6-\mathrm{G} 3$ vs. controls: $x^{2}=4.111672, d f=2, p=0.042641$} & \multicolumn{5}{|c|}{$12-G 2$ vs. $G 3: x^{2}=1.046887, d f=2, p=0.592509$} \\
\hline
\end{tabular}

Table 3: The ERCC4rs3136176 and ERCC4rs1799798 alleles and genotypes frequencies in patients with cervical squamous cell carcinoma (CSCC) well (G1), moderately (G2) and poorly (G3) differentiated and healthy women.

In case of SNP rs1799798, when the [GG] genotype was used as reference group, we observed a trend toward increased risk of well differentiated (G1) CSCC in case of patients with [AA] genotype ( $\mathrm{p}_{\text {after }}$ Yate's correction $=0.09, \mathrm{OR}=7.71,95 \% \mathrm{CI}$ : $1.19-50.09$, Table 3). Stronger, but not statistically significant, association was seen when the recessive model $([\mathrm{AA}]+[\mathrm{GA}]$ vs. $[\mathrm{GG}])$ was conducted $(\mathrm{p}=0.06, \mathrm{OR}=2.31$, 95\% CI:0.94 - 5.69, Table 3).

We then investigated associations between the ERCC4 haplotypes (reconstructed in the order of rs3136176 and rs1799798). Haplotype
AA significantly increased risk of G1 CSCC ( $\mathrm{p}=0.01, \mathrm{OR}=2.507,95 \%$ CI: 1.191 - 5.274, Table 4). The increased risk of G3 CSCC was associated with haplotype TG $(\mathrm{p}=0.037, \mathrm{OR}=2.166,95 \% \mathrm{CI}: 1.032$ 4.543, Table 4), whereas haplotype AG decreased the risk of G1 as well as G3 CSCC ( $\mathrm{p}=0.02, \mathrm{OR}=0.497,95 \%$ CI: $0.269-0.917$ and $\mathrm{p}=0.017$, $\mathrm{OR}=0.422$, 95\% CI: $0.204-0.872$, respectively, Table 4).

\begin{tabular}{|l|l|l|l|l|l|l|l|l|l|}
\hline & Control group & G1 & G2 & G3 & & $\mathbf{x}^{2}$ & $\mathbf{p}$ & OR & $95 \% \mathrm{Cl}$ \\
\hline
\end{tabular}


Citation: Pawlak-Adamska E, Bartosinska M, Wlodarska-Polinska I, Ignatowicz-Pacyna A, Kornafel J, et al. (2014) Tagging SNPs in the Excision Repair Cross-Complementing Group 4 (ERCC4) Gene Increased Risk of Cervical Squamous Cell Carcinoma (CSCC) and Modulate the Disease Outcome. J Carcinog Mutagen 5: 172. doi:10.4172/2157-2518.1000172

Page 9 of 16

\begin{tabular}{|c|c|c|c|c|c|c|c|c|c|}
\hline \multicolumn{10}{|c|}{ ERCC4rs3136176 / ERCC4rs1799798 } \\
\hline A A & $45.89(0.111)$ & $11.00(0.239)$ & $22.98(0.129)$ & $5.00(0.156)$ & $\begin{array}{l}\text { Control vs. G1 } \\
\text { Control vs. G2 } \\
\text { Control vs. G3 } \\
\text { G1 vs. G2 } \\
\text { G1 vs. G3 } \\
\text { G2 vs. G3 }\end{array}$ & $\begin{array}{l}6.204 \\
0.378 \\
0.588 \\
3.437 \\
0.795 \\
0.173\end{array}$ & $\begin{array}{l}0.012770 \\
0.538724 \\
0.443270 \\
0.063750 \\
0.795 \\
0.677755\end{array}$ & $\begin{array}{l}2.507 \\
1.183 \\
1.477 \\
2.120 \\
0.795 \\
1.249\end{array}$ & $\begin{array}{l}1.191-5.274 \\
0.693-2.019 \\
0.542-4.024 \\
0.946-4.750 \\
0.183-1.899 \\
0.437-3.569\end{array}$ \\
\hline A G & $267.11(0.645)$ & $22.00(0.478)$ & $105.02(0.590)$ & $14.00(0.438)$ & $\begin{array}{l}\text { Control vs. G1 } \\
\text { Control vs. G2 } \\
\text { Control vs. G3 } \\
\text { G1 vs. G2 } \\
\text { G1 vs. G3 } \\
\text { G2 vs. G3 }\end{array}$ & $\begin{array}{l}5.153 \\
1.823 \\
5.691 \\
1.861 \\
0.126 \\
2.570\end{array}$ & $\begin{array}{l}0.023232 \\
0.176953 \\
0.017071 \\
0.172506 \\
0.722583 \\
0.108888\end{array}$ & $\begin{array}{l}0.497 \\
0.780 \\
0.422 \\
0.637 \\
0.849 \\
0.540\end{array}$ & $\begin{array}{l}0.269-0.917 \\
0.544-1.119 \\
0.204-0.872 \\
0.332-1.221 \\
0.343-2.102 \\
0.253-1.155\end{array}$ \\
\hline T G & $98.89(0.239)$ & $13.00(0.283)$ & $49.98(0.281)$ & $13.00(0.406$ & $\begin{array}{l}\text { Control vs. G1 } \\
\text { Control vs. G2 } \\
\text { Control vs. G3 } \\
\text { G1 vs. G2 } \\
\text { G1 vs. G3 } \\
\text { G2 vs. G3 }\end{array}$ & $\begin{array}{l}0.405 \\
1.093 \\
4.348 \\
0.001 \\
1.298 \\
2.032\end{array}$ & $\begin{array}{l}0.524449 \\
0.295801 \\
0.037069 \\
0.980831 \\
0.254545 \\
0.154011\end{array}$ & $\begin{array}{l}1.247 \\
1.236 \\
2.166 \\
1.009 \\
1.737 \\
1.752\end{array}$ & $\begin{array}{l}0.631-2.462 \\
0.831-1.839 \\
1.032-4.543 \\
0.491-2.073 \\
0.669-4.508 \\
0.805-3.813\end{array}$ \\
\hline TA & $2.11(0.005)$ & $0.00(0.000)$ & $0.02(0.000)$ & $0.00(0.000))$ & $\begin{array}{l}\text { Control vs. G1 } \\
\text { Control vs. G2 } \\
\text { Control vs. G3 } \\
\text { G1 vs. G2 } \\
\text { G1 vs. G3 } \\
\text { G2 vs. G3 }\end{array}$ & $\begin{array}{l}- \\
- \\
- \\
- \\
- \\
-\end{array}$ & $\begin{array}{l}- \\
- \\
- \\
- \\
- \\
-\end{array}$ & $\begin{array}{l}- \\
- \\
- \\
- \\
- \\
-\end{array}$ & $\begin{array}{l}- \\
- \\
- \\
- \\
- \\
-\end{array}$ \\
\hline $\begin{array}{l}\text { Glob } \\
\text { Contr } \\
\text { Contr } \\
\text { Contr } \\
\text { G1 vs } \\
\text { G1 vs } \\
\text { G2 vs }\end{array}$ & $\begin{array}{l}\text { result: total Cont } \\
\text { vs. G1: } X^{2} \text { Global } \\
\text { vs. G2: } X^{2} \text { Global } \\
\text { vs. G3: } X^{2} \text { Global }= \\
\text { G2: } X^{2} \text { Global }=3.7 \\
\text { G3: }: X^{2} \text { Global }=1 . \\
\text { G3: } X^{2} \text { Global }^{2}=2.6\end{array}$ & $\begin{array}{l}\text { 414.0, total } \mathrm{G} 1= \\
38241, \mathrm{df}=2 \text { (fre } \\
23813, \mathrm{df}=2 \text { (fre } \\
59575, \mathrm{df}=2 \text { (fre } \\
\begin{array}{l}21, \mathrm{df}=2 \text { (frequer } \\
32, \mathrm{df}=2 \text { (freque } \\
30, \mathrm{df}=2 \text { (frequer }\end{array}\end{array}$ & $\begin{array}{l}0 \text {, total } G 2=178 \\
\text { ency }<0.03 \text { in bot } \\
\text { ency }<0.03 \text { in bot } \\
\text { ency }<0.03 \text { in bot } \\
<0.03 \text { in both } G 1 \\
<<0.03 \text { in both } G \\
<0.03 \text { in both } G 2\end{array}$ & $\begin{array}{l}\text { total } G 3=32.0 \\
\text { ontrol \& } G 1 \text { has } \\
\text { ontrol \& } G 2 \text { has } \\
\text { ontrol \& } G 3 \text { has } \\
G 2 \text { has been dr } \\
\text { G3 has been d } \\
G 3 \text { has been dr }\end{array}$ & $\begin{array}{l}\text { n dropped), } p_{\text {Fish }} \\
n \text { dropped), } p_{\text {Fish }} \\
n \text { dropped), } p_{\text {Fish }} \\
\text { ed), } p_{\text {Fisher's }}=0.1 \\
\text { ped), } p_{\text {Fisher's }}=0 . \\
\text { ed), } \text { p }_{\text {Fisher's }}=0.2\end{array}$ & $\begin{array}{l}0.0220 \\
0.4018 \\
0.0535 \\
39, p_{\text {Pear }} \\
219, p_{\text {Pe }} \\
17, p_{\text {Pear }}\end{array}$ & $\begin{array}{l}\text { Pearson's }=0 . \\
\text { Pearson's }=0 . \\
\text { Pearson's }=0 . \\
=0.155531 \\
\text { 's }=0.457219 \\
=0.261123\end{array}$ & $\begin{array}{l}947 \\
758 \\
408\end{array}$ & \\
\hline
\end{tabular}

Table 4: ERCC4rs3136176 and ERCC4rs1799798 haplotype frequencies in patients with cervical squamous cell carcinoma (CSCC) well (G1), moderately (G2) and poorly (G3) differentiated and healthy women.

Stratification by histological subtypes of CSCC showed that the rs3136176 may be associated with carcinoma planoepitheliale akeratodes (Cpa) (Table 5). When the [AA] genotype was used as reference group, we observed a significant increased frequency of [TT] genotype in patients with Cpa as compared to healthy women ( $\mathrm{p}_{\text {after }}$
Yate's correction $=0.03, \mathrm{OR}=2.71,95 \% \mathrm{CI}: 1.08-6.82$, Table 5). Similar association was seen when the dominant model ([AA] $+[\mathrm{GA}]$ vs. [GG]) was conducted $(\mathrm{p}=0.02, \mathrm{OR}=2.74,95 \% \mathrm{CI}: 1.12-6.72$, Table $5)$.

\begin{tabular}{|l|l|l|l|l|l|l|l|l|}
\hline & $\begin{array}{l}\text { Control group } \\
n=207 \\
n(\%)\end{array}$ & $\begin{array}{l}\text { Cpk } \\
n=33 \\
n(\%)\end{array}$ & $\begin{array}{l}\text { Cpa } \\
n=90 \\
n(\%)\end{array}$ & p & & OR & 95\%Cl \\
\hline rs3136176 & nenotype & $116(56.0)$ & $19(57.6)$ & $47(52.2)$ & & $n s^{1}$ & referent \\
\hline [AA] &
\end{tabular}


Citation: Pawlak-Adamska E, Bartosinska M, Wlodarska-Polinska I, Ignatowicz-Pacyna A, Kornafel J, et al. (2014) Tagging SNPs in the Excision Repair Cross-Complementing Group 4 (ERCC4) Gene Increased Risk of Cervical Squamous Cell Carcinoma (CSCC) and Modulate the Disease Outcome. J Carcinog Mutagen 5: 172. doi:10.4172/2157-2518.1000172

Page 10 of 16

\begin{tabular}{|c|c|c|c|c|c|c|c|c|}
\hline [AT] & $81(39.2)$ & $12(36.4)$ & $32(35.6)$ & $\begin{array}{l}\text { Cpk vs. Cpa } \\
\text { Control vs. Cpk } \\
\text { Control vs.Cpa }\end{array}$ & \multirow[t]{2}{*}{$\begin{array}{l}n s^{2} \\
n s^{3}\end{array}$} & $\begin{array}{l}0.86 \\
0.80 \\
1.00\end{array}$ & $\begin{array}{l}0.93 \\
0.90 \\
0.98\end{array}$ & $\begin{array}{l}0.40-2.17 \\
0.42-1.97 \\
0.57-1.66\end{array}$ \\
\hline [TT] & $10(4.8)$ & $3(6.1)$ & $11(12.2)$ & $\begin{array}{l}\text { Cpk vs. Cpa } \\
\text { Cpk vs. Control } \\
\text { Cpa vs. Control }\end{array}$ & & $\begin{array}{l}0.82^{*} \\
0.64^{*} \\
0.03\end{array}$ & $\begin{array}{l}1.48 \\
1.83 \\
2.71\end{array}$ & $\begin{array}{l}0.37-5.91 \\
0.46-7.27 \\
1.08-6.82\end{array}$ \\
\hline \multicolumn{9}{|l|}{ Allele } \\
\hline$[\mathrm{A}]$ & $313(75.6)$ & $50(75.8)$ & $126(70.0)$ & $\begin{array}{l}\text { Cpk vs. Cpa } \\
\text { Control vs.Cpk } \\
\text { Control vs.Cpa }\end{array}$ & & $\begin{array}{l}0.38 \\
1.00 \\
0.17\end{array}$ & $\begin{array}{l}0.75 \\
1.02 \\
0.76\end{array}$ & $\begin{array}{l}0.39-1.43 \\
0.56-1.87 \\
0.52-1.13\end{array}$ \\
\hline$[T]$ & $101(24.4)$ & $16(24.2)$ & $54(30.0)$ & $\begin{array}{l}\text { Cpk vs. Cpa } \\
\text { Cpk vs. Control } \\
\text { Cpa vs. Control }\end{array}$ & & $\begin{array}{l}0.38 \\
1.00 \\
0.17\end{array}$ & $\begin{array}{l}1.34 \\
0.98 \\
1.31\end{array}$ & $\begin{array}{l}0.70-2.56 \\
0.53-1.79 \\
0.89-1.94\end{array}$ \\
\hline \multicolumn{9}{|c|}{ Dominant model } \\
\hline \multirow[t]{2}{*}{$\begin{array}{l}{[A A]+[A T]} \\
\text { vs. } \\
{[T T]}\end{array}$} & $197(95.2)$ & 31 (93.9) & $79(87.8)$ & $\begin{array}{l}\text { Cpk vs. Cpa } \\
\text { Control vs.Cpk } \\
\text { Control vs.Cpa }\end{array}$ & & $\begin{array}{l}0.83 \\
0.59 \\
0.02\end{array}$ & $\begin{array}{l}0.70 \\
0.52 \\
0.36\end{array}$ & $\begin{array}{l}0.18-2.66 \\
0.14-2.01 \\
0.15-0.89\end{array}$ \\
\hline & $10(4.8)$ & $3(6.1)$ & $11(12.2)$ & $\begin{array}{l}\text { Cpk vs. Cpa } \\
\text { Control vs.Cpk } \\
\text { Control vs.Cpa }\end{array}$ & & $\begin{array}{l}0.83 \\
0.59 \\
0.02\end{array}$ & $\begin{array}{l}1.44 \\
1.91 \\
2.74\end{array}$ & $\begin{array}{l}0.38-5.51 \\
0.50-7.32 \\
1.12-6.72\end{array}$ \\
\hline \multicolumn{9}{|c|}{ Recessive model } \\
\hline \multirow[t]{2}{*}{$\begin{array}{l}{[T T]+[A T]} \\
\text { vs. } \\
{[A A]}\end{array}$} & $91(44.0)$ & $15(42.4)$ & $43(47.8)$ & $\begin{array}{l}\text { Cpk vs. Cpa } \\
\text { Cpk vs. Control } \\
\text { Cpa vs. Control }\end{array}$ & & $\begin{array}{l}0.72 \\
0.87 \\
0.60\end{array}$ & $\begin{array}{l}1.16 \\
0.99 \\
1.14\end{array}$ & $\begin{array}{l}0.52-2.45 \\
0.48-2.06 \\
0.70-1.88\end{array}$ \\
\hline & $116(56.0)$ & $19(57.6)$ & $47(52.2)$ & $\begin{array}{l}\text { Cpk vs. Cpa } \\
\text { Cpk vs. Control } \\
\text { Cpa vs. Control }\end{array}$ & & $\begin{array}{l}0.72 \\
0.87 \\
0.60\end{array}$ & $\begin{array}{l}0.86 \\
1.01 \\
0.87\end{array}$ & $\begin{array}{l}0.39-1.91 \\
0.49-2.09 \\
0.53-1.44\end{array}$ \\
\hline \multicolumn{9}{|l|}{ rs1799798 } \\
\hline \multicolumn{9}{|l|}{ Genotype } \\
\hline [GG] & $162(78.3)$ & $22(66.7)$ & $68(75.6)$ & & \multirow{3}{*}{$\begin{array}{l}\mathrm{ns}^{1} \\
\mathrm{~ns}^{2} \\
\mathrm{~ns}^{3}\end{array}$} & \multicolumn{3}{|c|}{ referent } \\
\hline$[\mathrm{GA}]$ & $42(20.3)$ & $9(27.3)$ & $20(22.2)$ & $\begin{array}{l}\text { Cpk vs. Cpa } \\
\text { Cpk vs. Control } \\
\text { Cpa vs. Control }\end{array}$ & & $\begin{array}{l}0.48 \\
0.29 \\
0.68\end{array}$ & $\begin{array}{l}0.72 \\
1.58 \\
1.13\end{array}$ & $\begin{array}{l}0.29-1.81 \\
0.68-3.68 \\
0.62-2.07\end{array}$ \\
\hline$[\mathrm{AA}]$ & $3(1.4)$ & $2(6.1)$ & $2(2.2)$ & $\begin{array}{l}\text { Cpk vs. Cpa } \\
\text { Cpk vs. Control } \\
\text { Cpa vs. Control }\end{array}$ & & $\begin{array}{l}0.57^{\star} \\
0.24^{*} \\
1.00^{*}\end{array}$ & $\begin{array}{l}0.32 \\
4.91 \\
1.59\end{array}$ & $\begin{array}{l}0.04-2.43 \\
0.78-31.03 \\
0.26-9.72\end{array}$ \\
\hline \multicolumn{9}{|l|}{ Allele } \\
\hline$[\mathrm{G}]$ & $366(88.4)$ & $53(80.3)$ & $156(86.7)$ & $\begin{array}{l}\text { Cpk vs. Cpa } \\
\text { Cpk vs. control } \\
\text { Cpa vs. Control }\end{array}$ & & $\begin{array}{l}0.22 \\
0.07 \\
0.55\end{array}$ & $\begin{array}{l}1.59 \\
0.53 \\
0.85\end{array}$ & $\begin{array}{l}0.76-3.35 \\
0.27-1.05 \\
0.50-1.44\end{array}$ \\
\hline$[\mathrm{A}]$ & $48(11.6)$ & $13(19.7)$ & $24(13.3)$ & $\begin{array}{l}\text { Cpk vs. Cpa } \\
\text { Cpk vs. control } \\
\text { Cpa vs. Control }\end{array}$ & & $\begin{array}{l}0.22 \\
0.07 \\
0.55\end{array}$ & $\begin{array}{l}0.63 \\
1.87 \\
1.17\end{array}$ & $\begin{array}{l}0.30-1.32 \\
0.95-3.68 \\
0.69-1.98\end{array}$ \\
\hline
\end{tabular}


Citation: Pawlak-Adamska E, Bartosinska M, Wlodarska-Polinska I, Ignatowicz-Pacyna A, Kornafel J, et al. (2014) Tagging SNPs in the Excision Repair Cross-Complementing Group 4 (ERCC4) Gene Increased Risk of Cervical Squamous Cell Carcinoma (CSCC) and Modulate the Disease Outcome. J Carcinog Mutagen 5: 172. doi:10.4172/2157-2518.1000172

Page 11 of 16

\begin{tabular}{|c|c|c|c|c|c|c|c|}
\hline \multicolumn{8}{|c|}{ Dominant model } \\
\hline \multirow{6}{*}{$\begin{array}{l}{[\mathrm{GG}]+[\mathrm{GA}]} \\
\text { vs. } \\
{[\mathrm{AA}]}\end{array}$} & 204 (98.6) & 31 (93.9) & $88(97.8)$ & Cpk vs. Cpa & $0.62^{*}$ & 2.84 & $0.38-21.02$ \\
\hline & & & & Cpk vs. control & $0.29^{*}$ & 0.23 & $0.04-1.42$ \\
\hline & & & & Cpa vs. Control & $0.63^{*}$ & 0.65 & $0.11-3.94$ \\
\hline & $3(1.4)$ & $2(6.1)$ & $2(2.2)$ & Cpk vs. Cpa & $0.62^{*}$ & 0.35 & $0.05-2.61$ \\
\hline & & & & Cpk vs. control & $0.29^{*}$ & 4.39 & $0.71-27.31$ \\
\hline & & & & Cpa vs. Control & $0.63^{*}$ & 1.55 & $0.25-9.41$ \\
\hline \multicolumn{8}{|c|}{ Recessive model } \\
\hline \multirow{6}{*}{$\begin{array}{l}{[A A]+[G A]} \\
\text { vs. } \\
{[G G]}\end{array}$} & $45(21.7)$ & $11(33.3)$ & $22(24.4)$ & Cpk vs. Cpa & 0.32 & 0.65 & $0.27-1.54$ \\
\hline & & & & Cpk vs. control & 0.14 & 1.80 & $0.81-3.99$ \\
\hline & & & & Cpa vs. Control & 0.61 & 0.86 & $0.48-1.54$ \\
\hline & $162(78.3)$ & $22(66.7)$ & $68(75.6)$ & Cpk vs. Cpa & 0.32 & 1.55 & $0.65-3.69$ \\
\hline & & & & Cpk vs. control & 0.14 & 0.56 & $0.25-1.23$ \\
\hline & & & & Cpa vs. Control & 0.61 & 1.16 & $0.65-2.09$ \\
\hline \multicolumn{8}{|c|}{ ^-p-value after Bonferroni correction } \\
\hline \multicolumn{8}{|c|}{ * - p-value after Yate's correction; \#- global p-value for genotype; } \\
\hline \multicolumn{8}{|l|}{ rs3136176 } \\
\hline \multicolumn{8}{|c|}{$1-$ Cpk vs. Cpa: $x^{2}=1.000745, d f=2, p=0.606335$} \\
\hline \multicolumn{8}{|c|}{$2-$ Cpk vs. controls: $x^{2}=0.154262, d f=2, p=0.925770$} \\
\hline \multicolumn{8}{|c|}{${ }^{3}-$ Cpa vs. controls: $x^{2}=5.223751, d f=2, p=0.073497$} \\
\hline \multicolumn{8}{|c|}{ rs1799798 } \\
\hline \multicolumn{8}{|c|}{4 - Cpk vs. Cpa: $x^{2}=1.615913, d f=2, p=0.445826$} \\
\hline \multicolumn{8}{|c|}{5 - Cpk vs. controls: $x^{2}=4.057297, d f=2, p=0.131621$} \\
\hline \multicolumn{8}{|c|}{6 - Cpa vs. controls: $x^{2}=0.394092, d f=2, p=0.821159$} \\
\hline
\end{tabular}

Table 5: ERCC4rs3136176 and ERCC4rs1799798 alleles and genotypes frequencies in cervical squamous cell carcinoma (CSCC): carcinoma planoepitheliale keratodes (Cpk), and carcinoma planoepitheliale aceratodes (Cpa) and healthy women.

rs1799798 SNP was not associated with histological subtypes of CSCC (Table 5), but we noted a trend toward different distribution of allele at this SNP between healthy women and patients with carcinoma planoepitheliale keratodes (Cpk) ( $\mathrm{p}=0.07$, Table 5).

In case of the ERCC4 haplotypes we noted a significant increased risk of $\mathrm{Cpk}$ when the $\mathrm{AA}$ haplotype was present $(\mathrm{p}=0.049, \mathrm{OR}=1.956$,
95\% CI: 0.991 - 3.861, Table 6). In contrast, the haplotype AG tended to decreased risk of carcinoma planoepitheliale akeratodes (Cpa) ( $\mathrm{p}=$ $0.059, \mathrm{OR}=0.709,95 \%$ CI:0.496 - 1.014, Table 6).

\begin{tabular}{|c|c|c|c|c|c|c|c|c|}
\hline & Control group & Cpk & Cpa & & $x^{2}$ & $\mathbf{p}$ & OR & $95 \% \mathrm{Cl}$ \\
\hline \multicolumn{9}{|c|}{ ERCC4rs3136176 / ERCC4rs1799798 } \\
\hline A A & $45.89(0.111)$ & $13.00(0.197)$ & $23.99(0.133)$ & $\begin{array}{l}\text { Cpk vs. Cpa } \\
\text { Cpk vs. Control group } \\
\text { Cpa vs. Control group }\end{array}$ & $\begin{array}{l}1.534 \\
3.854 \\
0.575\end{array}$ & $\begin{array}{l}0.215556 \\
0.049650 \\
0.448350\end{array}$ & $\begin{array}{l}0.627 \\
1.956 \\
1.226\end{array}$ & $\begin{array}{l}0.298-1.319 \\
0.991-3.861 \\
0.723-2.080\end{array}$ \\
\hline A G & $267.11(0.645)$ & $37.00(0.561)$ & $102.01(0.567)$ & $\begin{array}{l}\text { Cpk vs. Cpa } \\
\text { Cpk vs. Control group } \\
\text { Cpa vs. Control group }\end{array}$ & $\begin{array}{l}0.007 \\
1.899 \\
3.564\end{array}$ & $\begin{array}{l}0.931129 \\
0.168200 \\
0.059054\end{array}$ & $\begin{array}{l}1.025 \\
0.692 \\
0.709\end{array}$ & $\begin{array}{l}0.581-1.810 \\
0.408-1.171 \\
0.496-1.014\end{array}$ \\
\hline T G & $98.89(0.239)$ & $16.00(0.242)$ & $53.99(0.300)$ & $\begin{array}{l}\text { Cpk vs. Cpa } \\
\text { Cpk vs. Control group } \\
\text { Cpa vs. Control group }\end{array}$ & $\begin{array}{l}0.785 \\
0.002 \\
2.343\end{array}$ & $\begin{array}{l}0.375562 \\
0.967137 \\
0.125836\end{array}$ & $\begin{array}{l}1.339 \\
1.013 \\
1.356\end{array}$ & $\begin{array}{l}0.701-2.557 \\
0.552-1.858 \\
0.917-2.005\end{array}$ \\
\hline
\end{tabular}


Citation: Pawlak-Adamska E, Bartosinska M, Wlodarska-Polinska I, Ignatowicz-Pacyna A, Kornafel J, et al. (2014) Tagging SNPs in the Excision Repair Cross-Complementing Group 4 (ERCC4) Gene Increased Risk of Cervical Squamous Cell Carcinoma (CSCC) and Modulate the Disease Outcome. J Carcinog Mutagen 5: 172. doi:10.4172/2157-2518.1000172

\begin{tabular}{|l|l|l|l|l|l|l|l|}
\hline TA & $2.11(0.005)$ & $0.00(0.000)$ & $0.01(0.000)$ & $\begin{array}{l}\text { Cpk vs. Cpa } \\
\text { Cpk vs. Control group } \\
\text { Cpa vs. Control group }\end{array}$ & - & - & - \\
\end{tabular}

Table 6: ERCC4rs3136176 and ERCC4rs1799798 haplotype in cervical squamous cell carcinoma (CSCC): carcinoma planoepitheliale keratodes (Cpk), and carcinoma planoepitheliale aceratodes (Cpa) and healthy women.

We also found a link between genetic variants at rs3136176 SNP and the effect of treatment (Table 7). When the recessive model ([TT] $+[\mathrm{AT}]$ vs. $[\mathrm{AA}])$ was applied we observed that presence of $[\mathrm{T}]$ allele (genotype $[\mathrm{TT}]+[\mathrm{AT}]$ ) significantly decreased the disease remission rate $(\mathrm{p}=0.05, \mathrm{OR}=2.28,95 \% \mathrm{CI}: 0.99-5.26$, Table 7). Additionally, when the $[\mathrm{AA}]$ genotype was used as reference group, the same effect was observed for a heterozygous patients ( $\mathrm{p}=0.035, \mathrm{OR}=2.57,95 \% \mathrm{CI}$ : 1.06 - 6.27). The second studied SNP was not associated with remission rate in our group of patients, but it is noteworthy that [AA] genotype not occurred in patients with disease progression (Table 7). We also did not found any association between particular haplotype and remission rate (Table 8).

\begin{tabular}{|c|c|c|c|c|c|c|}
\hline & $\begin{array}{l}\text { CR } \\
(\mathrm{n}=77) \\
\mathrm{n}(\%)\end{array}$ & $\begin{array}{l}\text { PD } \\
(n=33) \\
n(\%)\end{array}$ & $\mathbf{p}_{\text {total }}^{\#}$ & p & OR & $95 \% \mathrm{Cl}$ \\
\hline \multicolumn{7}{|l|}{ rs3136176 } \\
\hline \multicolumn{7}{|l|}{ Genotype } \\
\hline$[\mathrm{AA}]$ & $46(59.7)$ & $13(39.4)$ & \multirow[t]{2}{*}{$n s^{1}$} & \multicolumn{3}{|c|}{ referent } \\
\hline $\begin{array}{l}{[\mathrm{AT}]} \\
{[\mathrm{TT}]}\end{array}$ & $\begin{array}{l}22(28.6) \\
9(11.7)\end{array}$ & $\begin{array}{l}16 \text { (48.5) } \\
4(12.1)\end{array}$ & & $\begin{array}{l}0.035 \\
0.76\end{array}$ & $\begin{array}{l}2.51 \\
0.64\end{array}$ & $\begin{array}{l}1.06-6.27 \\
0.17-2.40\end{array}$ \\
\hline \multicolumn{7}{|l|}{ Allele } \\
\hline $\begin{array}{l}{[A]} \\
{[T]}\end{array}$ & $\begin{array}{l}114(74.0) \\
40(26.0)\end{array}$ & $\begin{array}{l}42(63.6) \\
24(36.4)\end{array}$ & & 0.12 & $\begin{array}{l}0.61 \\
1.63\end{array}$ & $\begin{array}{l}0.33-1.14 \\
0.88-3.02\end{array}$ \\
\hline \multicolumn{7}{|c|}{ Dominant model } \\
\hline $\begin{array}{l}{[A A]+[A T]} \\
\text { vs. } \\
{[T T]}\end{array}$ & $\begin{array}{l}68(88.3) \\
9(11.7)\end{array}$ & $\begin{array}{l}29(87.9) \\
4(12.1)\end{array}$ & & $0.80^{*}$ & $\begin{array}{l}0.96 \\
1.00\end{array}$ & $\begin{array}{l}0.27-3.33 \\
0.30-3.66\end{array}$ \\
\hline \multicolumn{7}{|c|}{ Recessive model } \\
\hline $\begin{array}{l}{[\mathrm{TT}]+[\mathrm{AT}]} \\
\text { vs. } \\
{[\mathrm{AA}]}\end{array}$ & $\begin{array}{l}31(40.3) \\
46(59.7)\end{array}$ & $\begin{array}{l}20(60.6) \\
13(39.4)\end{array}$ & & 0.05 & $\begin{array}{l}2.28 \\
0.48\end{array}$ & $\begin{array}{l}0.99-5.26 \\
0.19-1.00\end{array}$ \\
\hline \multicolumn{7}{|l|}{ rs1799798 } \\
\hline \multicolumn{7}{|l|}{ Genotype } \\
\hline [GG] & $56(72.7)$ & $26(78.8)$ & $\mathrm{ns}^{2}$ & \multicolumn{3}{|c|}{ referent } \\
\hline $\begin{array}{l}{[\mathrm{GA}]} \\
{[\mathrm{AA}]}\end{array}$ & $\begin{array}{l}17(22.1) \\
4(5.2)\end{array}$ & $\begin{array}{l}7(21.2) \\
0(0.0)\end{array}$ & & $\begin{array}{l}0.81 \\
0.43\end{array}$ & $\begin{array}{l}0.89 \\
-\end{array}$ & $\begin{array}{l}0.33-2.40 \\
-\end{array}$ \\
\hline \multicolumn{7}{|l|}{ Allele } \\
\hline$[\mathrm{G}]$ & $129(83.8)$ & $59(89.4)$ & & 0.28 & 1.63 & $0.67-3.99$ \\
\hline
\end{tabular}


Citation: Pawlak-Adamska E, Bartosinska M, Wlodarska-Polinska I, Ignatowicz-Pacyna A, Kornafel J, et al. (2014) Tagging SNPs in the Excision Repair Cross-Complementing Group 4 (ERCC4) Gene Increased Risk of Cervical Squamous Cell Carcinoma (CSCC) and Modulate the Disease Outcome. J Carcinog Mutagen 5: 172. doi:10.4172/2157-2518.1000172

Page 13 of 16

\begin{tabular}{|c|c|c|c|c|c|}
\hline$[\mathrm{A}]$ & $25(16.2)$ & $7(10.6)$ & & 0.61 & $0.25-1.50$ \\
\hline \multicolumn{6}{|c|}{ Dominant model } \\
\hline $\begin{array}{l}{[G G]+[G A]} \\
\text { vs. } \\
{[A A]}\end{array}$ & $\begin{array}{l}73(94.8) \\
4(5.2)\end{array}$ & $\begin{array}{l}33(100.0) \\
0(0.0)\end{array}$ & $0.61^{*}$ & $\begin{array}{l}- \\
-\end{array}$ & - \\
\hline \multicolumn{6}{|c|}{ Recessive model } \\
\hline $\begin{array}{l}{[A A]+[G A]} \\
\text { vs. } \\
{[G G]}\end{array}$ & $\begin{array}{l}21(27.3) \\
56(72.7)\end{array}$ & $\begin{array}{l}7(21.2) \\
26(78.8)\end{array}$ & 0.50 & $\begin{array}{l}0.72 \\
1.39\end{array}$ & $\begin{array}{l}0.27-1.90 \\
0.53-3.69\end{array}$ \\
\hline $\begin{array}{l}{ }^{\wedge}-p \text {-value a } \\
{ }^{*}-p \text {-value a } \\
\#-\text { global } p \text { - } \\
1-x^{2}=4.43 \\
2-x^{2}=1.83\end{array}$ & & & & & \\
\hline
\end{tabular}

Table 7: ERCC4rs3136176 and ERCC4rs1799798 genotype and allele frequencies in squamous cell cervical cancer (CSCC) patients with disease remission $(\mathrm{CR})$ and disease progression $(\mathrm{PD})$.

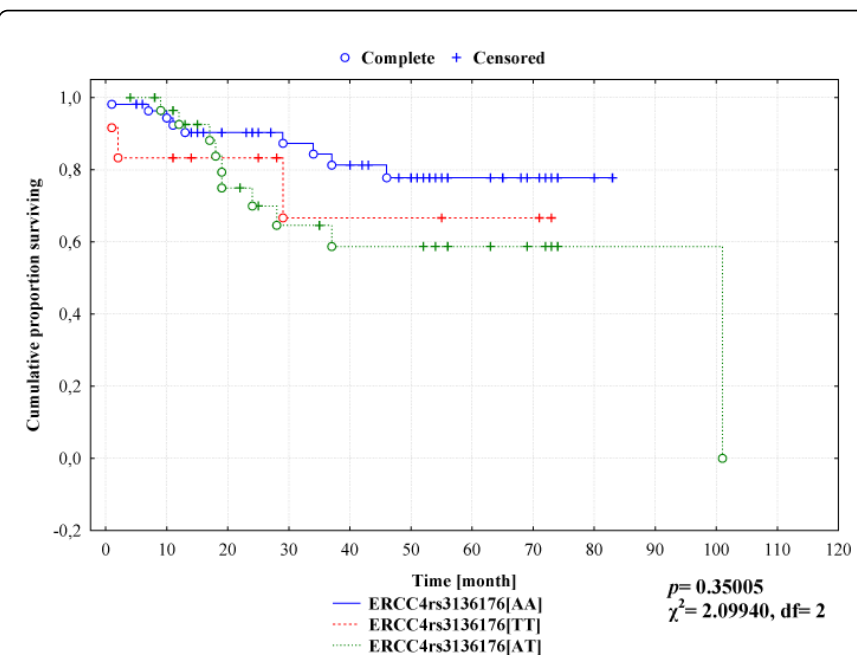

Figure 2. Cumulative proportion surviving in radically treated CSCC patient with the stage of the disease II and III stratified by ERCC4rs3136176 genotypes.

To evaluate the impact of the ERCC4 gene polymorphisms on the progression-free survival the Kaplan-Meier analysis was done. The median follow-up was 48 months for the patients after radical treatment. The actuarial 48-month progression-free survival was $74.5 \% \pm 6.4 \%$ for whole group of patients after radical treatment. Concerning the overall survival rates found using Kaplan-Meier method and log-rank test, we observed similar mean survival rates according to patients' genotypes at both studied SNPs (Figures 2-4).

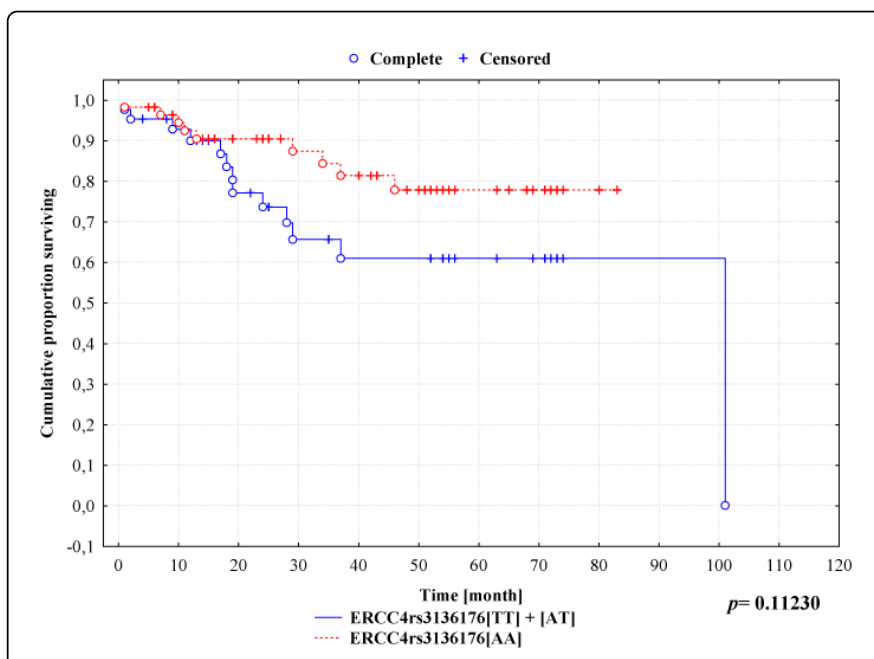

Figure 3. Cumulative proportion surviving in radically treated CSCC patient with the stage of the disease II and III stratified by ERCC4rs3136176 genotypes in recessive model.

\section{Discussion}

Given ascending proof that HPV infection is a major risk factor for cervical cancer [46], host genetic variations controlling cell division and maintenance of genome integrity may determine the risk of developing cervical cancer [47-49]. DNA repair systems act to maintain genome integrity in the face of replication errors, environmental insults, and the cumulative effects of age and an accumulation of damaged DNA are one of the way to cancer development. Sufficient DNA repair activity ensures the stability and fidelity of the genome when exposed to carcinogens in the process of cell growth and differentiation [50], whereas instability in the genome in cancer patients may indicate a possible involvement of defective 
Citation: Pawlak-Adamska E, Bartosinska M, Wlodarska-Polinska I, Ignatowicz-Pacyna A, Kornafel J, et al. (2014) Tagging SNPs in the Excision Repair Cross-Complementing Group 4 (ERCC4) Gene Increased Risk of Cervical Squamous Cell Carcinoma (CSCC) and Modulate the Disease Outcome. J Carcinog Mutagen 5: 172. doi:10.4172/2157-2518.1000172

Page 14 of 16

DNA repairing capacity [51]. Genes encoding proteins involved in the DNA repair systems are consider as a potential cancer risk factors. Especially, genetic variations within those genes, which may lead to abnormal function and/or expression of encoded proteins, are in special interests. Increasing studies have revealed that polymorphisms in the ERCC4 gene, interacting with environmental or other genetic factors, have association with many types of cancers [17-39].

\begin{tabular}{|c|c|c|c|c|c|c|}
\hline & CR & PD & $x^{2}$ & p & OR & $95 \% \mathrm{Cl}$ \\
\hline \multicolumn{7}{|c|}{ ERCC4rs3136176 / ERCC4rs1799798 } \\
\hline A A & $6.98(0.106)$ & $25.00(0.162)$ & 1.186 & 0.276164 & 0.611 & $0.250-1.493$ \\
\hline A G & $35.02(0.531)$ & $89.00(0.578)$ & 0.420 & 0.516996 & 0.826 & $0.462-1.474$ \\
\hline TA & $0.02(0.000)$ & $0.00(0.000)$ & - & - & - & - \\
\hline T G & $23.98(0.363)$ & $40.00(0.260)$ & 2.411 & 0.120473 & 1.628 & $0.878-3.018$ \\
\hline
\end{tabular}

Table 8. ERCC4rs3136176 and ERCC4rs1799798 haplotype frequencies squamous cell cervical cancer (CSCC) patients with disease remission (CR) and disease progression (PD).

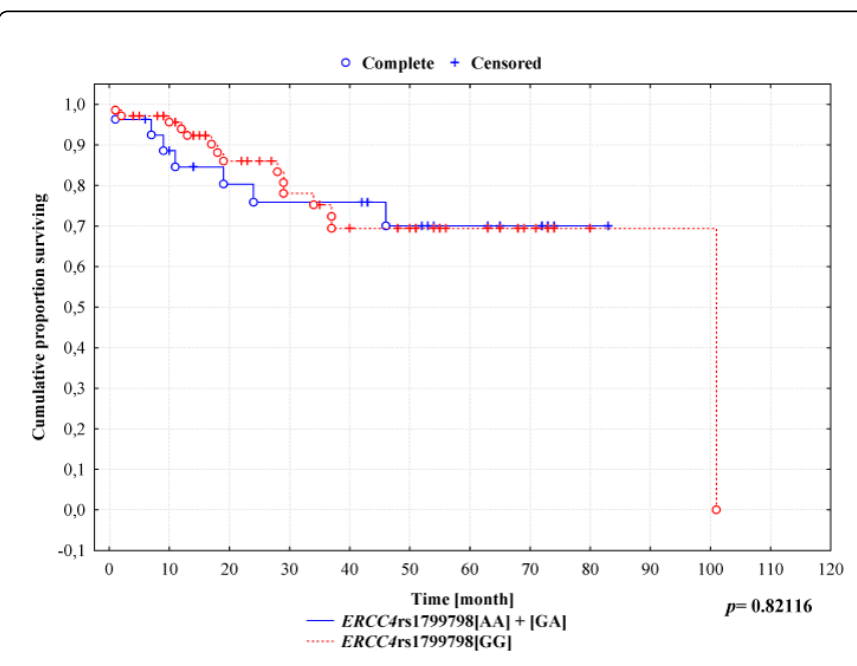

Figure 4. Cumulative proportion surviving in radically treated CSCC patient with the stage of the disease II and III stratified by ERCC4rs1799798 genotypes in recessive model.

This study indicates that variant types of DNA repair gene play partial roles in modifying individual susceptibility to cervical cancer. The polymorphic markers that we chose have been selected across preselected cancer-related genes and in Europeans identified as tagSNPs. In our work selected tagSNPs not only were risk factor of cervical squamous cell carcinoma but also modulates the course of disease. First proof for association of ERCC4 tagSNPs with CSCC was achieved from univariate analysis. In particular, observed diseaseprotective effect of ERCC4rs3136176 tagSNP is described for the first time in case of cervical squamous cell carcinoma. Moreover, detailed analysis showed that presence of $[\mathrm{A}]$ allele (genotype $[\mathrm{AA}]+[\mathrm{AT}]$ ) not only protects against CSCC, but also promote the disease remission and protects against development of poorly (G3) differentiated CSCC, which is linked with worse clinical outcome. Altogether this indicates that adenine at rs3136176 within intron 9 of ERCC4 gene may be considered as a protective factor against CSCC development.
Moreover, is also associated with good prognosis which may be informative factor for prognostic factor for CSCC patients. The second studied by us tagSNP rs1799798 has a weaker impact of overall CSCC as well as the clinical forecast and only tended to be associated with grade of tumor with the best prognosis: (G1) and with carcinoma planoepitheliale keratodes (Cpk) histologic subtype of tumor which is linked with better prognosis.

When we entertain the whole gene, effects of polymorphisms are best represented by their haplotypes and its analysis increases the power to detect disease associations because of higher heterozygosity and tighter linkage disequilibrium with disease-causing mutations. In addition, haplotype analysis offers the advantage of not assuming that any of the genotyped polymorphisms is functional; rather, it allows for the possibility of an ungenotyped functional variant to be in linkage disequilibrium with the genotyped polymorphisms [52].

Our research indicate that haplotype ERCC4rs3136176[A]/ ERCC4rs1799798[G] significantly decreased risk of G1 CSCC as well as G3 CSCC and only tended to decrease risk of CSCC as well as carcinoma planoepitheliale akeratodes (Cpa). In contrast haplotype AA significantly increased risk of G1 CSCC and risk of Cpk, whereas haplotype TG increased risk of G3 CSCC. Meanwhile, chosen tagSNPs are not a predictor factor in case of CSCC since the overall survival rates showed similar mean survival rates according to patients' genotypes at both studied SNPs.

Altogether this may indicate that ERCC4 tagSNPs are a CSCC risk as well as prognostic but not a predictor factor.

A few studies have investigated the associations between ERCC4 SNPs in cancers [17-36], but still there is no information in literature data applying ERCC4 in cervical squamous cell carcinoma. Only two studies analyzing relationship between ERCC4 and squamous cell carcinoma (SCC) but in case of head and neck cancer [35,36]. The obtained by $\mathrm{Yu}$ et al. [35] results indicated that some SNPs within ERCC4 gene are associated with SCCHN (i.e. rs3136038, rs2276466). The second available research, examining several DNA repair genes including ERCC4, did not reveal any association of studied ERCC4 SNP (rs1799801) with SCCHN [36]. To the best of the authors' knowledge, none of investigators studied the associations between 
Citation: Pawlak-Adamska E, Bartosinska M, Wlodarska-Polinska I, Ignatowicz-Pacyna A, Kornafel J, et al. (2014) Tagging SNPs in the Excision Repair Cross-Complementing Group 4 (ERCC4) Gene Increased Risk of Cervical Squamous Cell Carcinoma (CSCC) and Modulate the Disease Outcome. J Carcinog Mutagen 5: 172. doi:10.4172/2157-2518.1000172

Page 15 of 16

ERCC4 genetic variants and cancers examining the rs3136176 in case of cancer associations. Our important result is the first in worldwide literature data.

Till now only three studies analyzing the rs 1799798 SNP in cancers [26,31,37]. Shao et al. [26] did not reveal any association of this SNP in lung cancer. Similarly Michiels et al. [33] also did not found any association of rs1799798 with bladder cancer. This SNP also did not influenced risk of squamous cell carcinoma of the head and neck [37]. Identified by us weak association of rs 1799798 with CSCC has not been previously reported for any cancers and the functional significance of the variants is unknown. Thus, they need to be confirmed in future studies.

Perhaps, this phenomenon could be associated with the different pattern of ERCC4 expression in CSCC patients and potential influence of its level by studied SNPs. rs3136176 and rs1799798 tagSNPs are located within intron 9 and intron 1, respectively, and it is well known that SNPs mapped to introns most likely will not yield altered amino acid sequences, but they may still alter gene regulation in terms of transcription, splicing, and transcript turnover rates. To the best of author's knowledge the functional impact of those SPNs are still not known. So far, there is no literature data analyzing the ERCC4 expression in SCC in cervix as well as no information about the link between gene variation and expression pattern of ERCC4. However, existed data indicate a significant role of ERCC4 in next-generation personalized cancer therapy [10] and may be a crucial rate-limiting factor in DNA repair [11], but the final explanation of our observation needs further studies.

Moreover, because of the low number of patients in subgroups, our results achieved for association between studied polymorphisms and grade of differentiation need to be interpreted with caution $[53,54]$.

Concluding, to reveal the genetic susceptibility to cervical cancer, it is necessary to identify genetic risk markers that can predict the development of cervical cancer and modulate the disease outcome. Our population-based, case-control association study may indicate that ERCC4 tagSNPs are a CSCC risk as well as prognostic but not a predictor factors.

\section{Acknowledgments}

\section{Conflicts of interest}

The authors declare no conflicts of interest.

\section{References}

1. Parkin DM, Bray F, Ferlay J, Pisani P (2005) Global cancer statistics, 2002. CA Cancer J Clin 55: 74-108.

2. Doorbar J, Quint W, Banks L, Bravo IG, Stoler M, et al. (2012) The biology and life-cycle of human papillomaviruses. Vaccine 30 Suppl 5: F55-70.

3. Dasika GK, Lin SC, Zhao S, Sung P, Tomkinson A, et al. (1999) DNA damage-induced cell cycle checkpoints and DNA strand break repair in development and tumorigenesis. Oncogene 18: 7883-7899.

4. Ruttan CC, Glickman BW (2002) Coding variants in human doublestrand break DNA repair genes. Mutat Res 509: 175-200.

5. Schärer OD (2003) Chemistry and biology of DNA repair. Angew Chem Int Ed Engl 42: 2946-2974

6. Friedberg EC (2003) DNA damage and repair. Nature 421: 436-440.
7. Goode EL, Ulrich CM, Potter JD (2002) Polymorphisms in DNA repair genes and associations with cancer risk. Cancer Epidemiol Biomarkers Prev 11: 1513-1530.

8. Friedberg EC (2001) How nucleotide excision repair protects against cancer. Nat Rev Cancer 1: 22-33.

9. Hoeijmakers JH (2001) Genome maintenance mechanisms for preventing cancer. Nature 411: 366-374.

10. Ahmad A, Robinson AR, Duensing A, van Drunen E, Beverloo HB, et al. (2008) ERCC1-XPF endonuclease facilitates DNA double-strand break repair. Mol Cell Biol 28: 5082-5092.

11. Rahn JJ, Adair GM, Nairn RS (2010) Multiple roles of ERCC1-XPF in mammalian interstrand crosslink repair. Environ Mol Mutagen 51: 567-581

12. Vaezi A, Wang X, Buch S, Gooding W, Wang L, et al. (2011) XPF expression correlates with clinical outcome in squamous cell carcinoma of the head and neck. Clin Cancer Res 17: 5513-5522.

13. Wei Q, Wang LE, Sturgis EM, Mao L (2005) Expression of nucleotide excision repair proteins in lymphocytes as a marker of susceptibility to squamous cell carcinomas of the head and neck. Cancer Epidemiol Biomarkers Prev 14: 1961-1966.

14. Planchard D, Domont J, Taranchon E, Monnet I, Tredaniel J, et al. (2009) The NER proteins are differentially expressed in ever smokers and in never smokers with lung adenocarcinoma. Ann Oncol 20: 1257-1263.

15. Köberle B, Ditz C, Kausch I, Wollenberg B, Ferris RL, et al. (2010) Metastases of squamous cell carcinoma of the head and neck show increased levels of nucleotide excision repair protein XPF in vivo that correlate with increased chemoresistance ex vivo. Int J Oncol 36: 1277-1284.

16. Liu C, Zhou S, Begum S, Sidransky D, Westra WH, et al. (2007) Increased expression and activity of repair genes TDP1 and XPF in non-small cell lung cancer. Lung Cancer 55: 303-311.

17. Chang LC, Sheu HM, Huang YS, Kuo KW (2000) Quantitative determination of the expression of xeroderma pigmentosum $\mathrm{F}$ gene in human nonmelanoma skin cancers. Biochem Biophys Res Commun 273: 454-458.

18. Langer R, Specht K, Becker K, Ewald P, Sarbia M, et al. (2004) [Prediction of response to neoadjuvant chemotherapy in Barrett's carcinoma by quantitative gene expression analysis]. Verh Dtsch Ges Pathol 88: 207-213.

19. Kohlhase S, Bogdanova NV, Schürmann P1 Bermisheva M, Khusnutdinova E, et al. (2014) Mutation analysis of the ERCC4/FANCQ gene in hereditary breast cancer. PLoS One 9: e85334.

20. Romanowicz-Makowska H, Smolarz B, Kulig A (2007) [Polymorphisms in XRCC1 and ERCC4/XPF DNA repair genes and associations with breast cancer risk in women]. Pol Merkur Lekarski 22: 200-203.

21. Crew KD, Gammon MD, Terry MB, Zhang FF, Zablotska LB, et al (2007) Polymorphisms in nucleotide excision repair genes, polycyclic aromatic hydrocarbon-DNA adducts, and breast cancer risk. Cancer Epidemiol Biomarkers Prev 16: 2033-2041.

22. Smith TR, Levine EA, Perrier ND, Miller MS, Freimanis RI, et al. (2003) DNA-repair genetic polymorphisms and breast cancer risk. Cancer Epidemiol Biomarkers Prev 12: 1200-1204.

23. Lee SA, Lee KM, Park WY, Kim B, Nam J, et al. (2005) Obesity and genetic polymorphism of ERCC2 and ERCC4 as modifiers of risk of breast cancer. Exp Mol Med 37: 86-90.

24. Milne RL, Ribas G, González-Neira A, Fagerholm R, Salas A, et al. (2006) ERCC4 associated with breast cancer risk: a two-stage case-control study using high-throughput genotyping. Cancer Res 66: 9420-9427.

25. Gaudet MM, Milne RL, Cox A, Camp NJ, Goode EL, et al. (2009) Five polymorphisms and breast cancer risk: results from the Breast Cancer Association Consortium. Cancer Epidemiol Biomarkers Prev 18: 1610-1616.

26. Osorio A, Milne RL, Pita G, Peterlongo P, Heikkinen T, et al. (2009) Evaluation of a candidate breast cancer associated SNP in ERCC4 as a risk modifier in BRCA1 and BRCA2 mutation carriers. Results from the 
Citation: Pawlak-Adamska E, Bartosinska M, Wlodarska-Polinska I, Ignatowicz-Pacyna A, Kornafel J, et al. (2014) Tagging SNPs in the Excision Repair Cross-Complementing Group 4 (ERCC4) Gene Increased Risk of Cervical Squamous Cell Carcinoma (CSCC) and Modulate the Disease Outcome. J Carcinog Mutagen 5: 172. doi:10.4172/2157-2518.1000172

Page 16 of 16

Consortium of Investigators of Modifiers of BRCA1/BRCA2 (CIMBA). Br J Cancer 101: 2048-2054.

27. Weiss JM, Weiss NS, Ulrich CM, Doherty JA, Voigt LF, et al. (2005) Interindividual variation in nucleotide excision repair genes and risk of endometrial cancer. Cancer Epidemiol Biomarkers Prev 14: 2524-2530.

28. Shao M, Ma H, Wang Y, Xu L, Yuan J, et al. (2008) Polymorphisms in excision repair cross-complementing group 4 (ERCC4) and susceptibility to primary lung cancer in a Chinese Han population. Lung Cancer 60: 332-339.

29. Zienolddiny S, Campa D, Lind H, Ryberg D, Skaug V, et al. (2006) Polymorphisms of DNA repair genes and risk of non-small cell lung cancer. Carcinogenesis 27: 560-567.

30. Winsey SL, Haldar NA, Marsh HP, Bunce M, Marshall SE, et al. (2000) A variant within the DNA repair gene XRCC3 is associated with the development of melanoma skin cancer. Cancer Res 60: 5612-5616.

31. McWilliams RR, Bamlet WR, Cunningham JM, Goode EL, de Andrade $\mathrm{M}$, et al. (2008) Polymorphisms in DNA repair genes, smoking, and pancreatic adenocarcinoma risk. Cancer Res 68: 4928-4935.

32. Abbasi R, Ramroth H, Becher H, Dietz A, Schmezer P, et al. (2009) Laryngeal cancer risk associated with smoking and alcohol consumption is modified by genetic polymorphisms in ERCC5, ERCC6 and RAD23B but not by polymorphisms in five other nucleotide excision repair genes. Int J Cancer 125: 1431â€“1439.

33. Lu B, Li J, Gao Q, Yu W, Yang Q, et al. (2014) Laryngeal cancer risk and common single nucleotide polymorphisms in nucleotide excision repair pathway genes ERCC1, ERCC2, ERCC3, ERCC4, ERCC5 and XPA. Gene 542: 64-68.

34. García-Closas M, Malats N, Real FX, Welch R, Kogevinas M, et al. (2006) Genetic variation in the nucleotide excision repair pathway and bladder cancer risk. Cancer Epidemiol Biomarkers Prev 15: 536-542.

35. Michiels S, Laplanche A, Boulet T, Dessen P, Guillonneau B, et al. (2009) Genetic polymorphisms in 85 DNA repair genes and bladder cancer risk. Carcinogenesis 30: 763-768.

36. Matullo G, Guarrera S, Sacerdote C, Polidoro S, Davico L, et al. (2005) Polymorphisms/haplotypes in DNA repair genes and smoking: a bladder cancer case-control study. Cancer Epidemiol Biomarkers Prev 14: 2569-2578.

37. Huang WY, Berndt SI, Kang D, Chatterjee N, Chanock SJ, et al. (2006) Nucleotide excision repair gene polymorphisms and risk of advanced colorectal adenoma: XPC polymorphisms modify smoking-related risk. Cancer Epidemiol Biomarkers Prev 15: 306-311.

38. Moreno V, Gemignani F, Landi S, Gioia-Patricola L, Chabrier A, et al. (2006) Polymorphisms in genes of nucleotide and base excision repair: risk and prognosis of colorectal cancer. Clin Cancer Res 12: 2101-2108.

39. Yu H, Liu Z, Huang YJ, Yin M, Wang LE, et al. (2012) Association between single nucleotide polymorphisms in ERCC4 and risk of squamous cell carcinoma of the head and neck. PLoS One 7: e41853.

40. Azad AK, Bairati I, Samson E, Cheng D, Mirshams M, et al. (2012) Validation of genetic sequence variants as prognostic factors in early- stage head and neck squamous cell cancer survival. Clin Cancer Res 18: 196-206.

41. Wyss AB, Weissler MC, Avery CL, Herring AH, Bensen JT, et al. (2014) Single nucleotide polymorphisms in nucleotide excision repair genes, cancer treatment, and head and neck cancer survival. Cancer Causes Control 25: 437-450.

42. Tavassoli FA, Deville P (2003) World Health Organization classification of tumours. Pathology and genetics of tumours of the breast and female genital organs. Lyonâ $€^{\mathrm{mt}}$ IARC Press 138-139.

43. International Federation of Gynecology and Obstetrics. (1989) FIGO stagesâ€"1988 revision. Gynecol Oncol 35: 125-127.

44. Pawlak E, Karabon L, Wlodarska-Polinska I, Jedynak A, Jonkisz A, et al. (2010) Influence of CTLA-4/CD28/ICOS gene polymorphisms on the susceptibility to cervical squamous cell carcinoma and stage of differentiation in the Polish population. Hum Immunol 71: 195-200.

45. Xu Z, Kaplan NL, Taylor JA (2007) TAGster: efficient selection of LD tag SNPs in single or multiple populations. Bioinformatics 23: 3254-3255.

46. Shi YY, He L (2005) SHEsis, a powerful software platform for analyses of linkage disequilibrium, haplotype construction, and genetic association at polymorphism loci. Cell Res 15: 97-98.

47. Li Z, Zhang Z, He Z, Tang W, Li T, et al. (2009) A partition-ligationcombination-subdivision EM algorithm for haplotype inference with multiallelic markers: update of the SHEsis (http://analysis.bio-x.cn). Cell Res 19: 519-523.

48. Moreno V, Bosch FX, Muñoz N, Meijer CJ, Shah KV, et al. (2002) Effect of oral contraceptives on risk of cervical cancer in women with human papillomavirus infection: the IARC multicentric case-control study. Lancet 359: 1085-1092.

49. Benjamin I, Saigo P, Finstad C, Takahashi H, Federici M, et al. (1996) Expression and mutational analysis of P53 in stage IB and IIA cervical cancers. Am J Obstet Gynecol 175: 1266-1271.

50. Kim JW, Roh JW, Park NH, Song YS, Kang SB, et al. (2001) Polymorphism of TP53 codon 72 and the risk of cervical cancer among Korean women. Am J Obstet Gynecol 184: 55-58.

51. Singh H, Sachan R, Devi S, Pandey SN, Mittal B (2008) Association of GSTM1, GSTT1, and GSTM3 gene polymorphisms and susceptibility to cervical cancer in a North Indian population. Am J Obstet Gynecol 198: 303.

52. Hong MY, Chapkin RS, Wild CP, Morris JS, Wang N, et al. (1999) Relationship between DNA adduct levels, repair enzyme, and apoptosis as a function of DNA methylation by azoxymethane. Cell Growth Differ 10: 749-758.

53. Barnes DE, Lindahl $\mathrm{T}$ (2004) Repair and genetic consequences of endogenous DNA base damage in mammalian cells. Annu Rev Genet 38: 445-476.

54. Monographs in Epidemiology and Biostatistics. New York: Oxford University Press. 